Dredging Operations and Environmental Research Program

\title{
Combining the ICM Eutrophication Model with the SEDZLJ Sediment Transport Model
}

Carl F. Cerco

August 2012

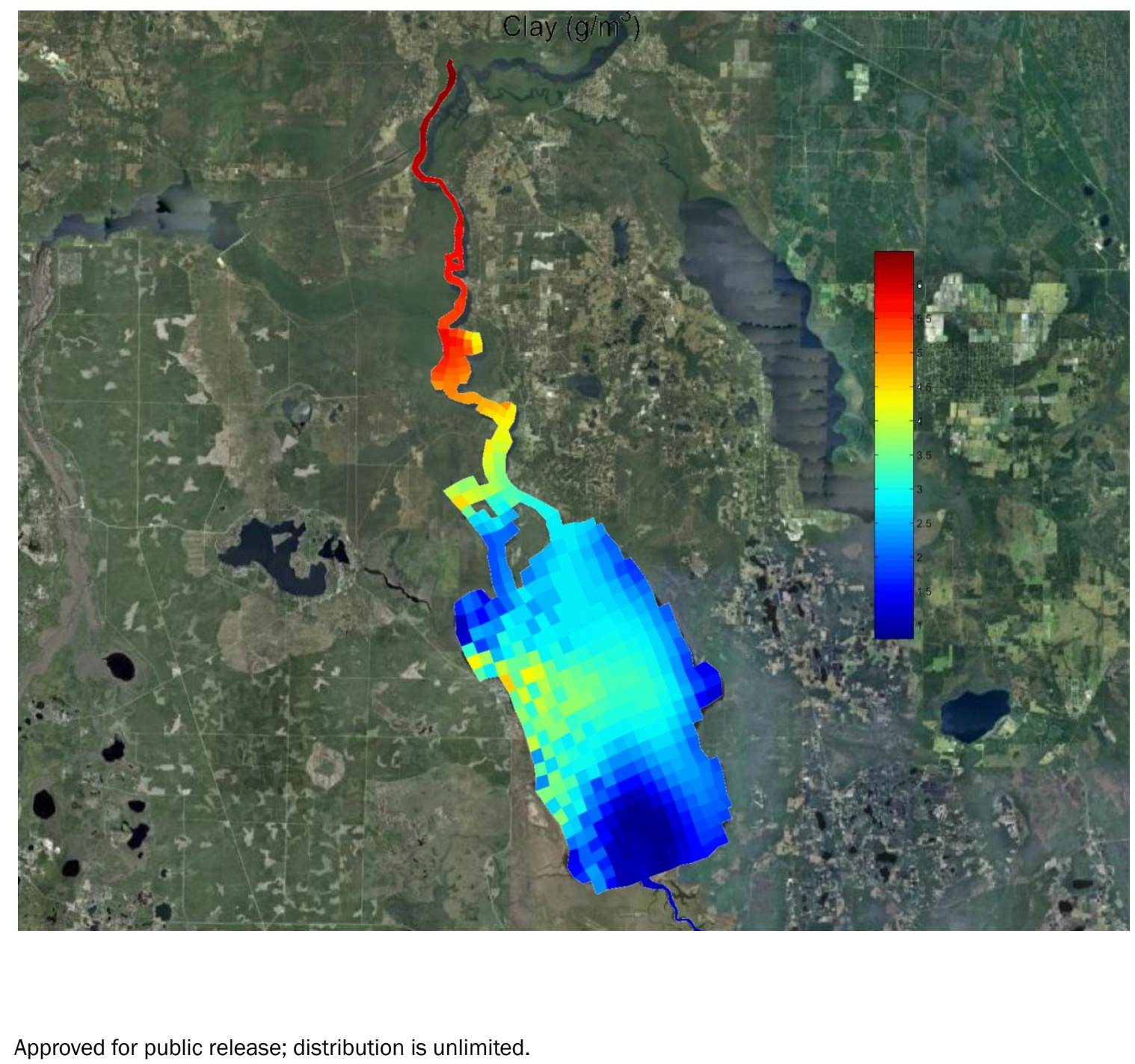




\title{
Combining the ICM Eutrophication Model with the SEDZLJ Sediment Transport Model
}

\author{
Carl F. Cerco
}

Environmental Laboratory

U.S. Army Engineer Research and Development Center

3909 Halls Ferry Road

Vicksburg, MS 39180

Final report

Approved for public release; distribution is unlimited. 


\section{Abstract}

This report describes the formulation of the SEDZLJ sediment transport model, coupling of the model with the ICM eutrophication model, validation of the combined codes on a simplified grid, and application of the combined codes to a prototype system.

The code validation tests indicate the codes are correctly coupled. The combined codes meet specified performance criteria including:

1. Mass conservation in water and bed.

2. Limited sensitivity to variations in model time-step.

3. Settling of new ICM state variables through model water column agrees with settling of original ICM state variables.

4. Transport of new ICM state variables agrees with transport of original ICM state variables.

5. Sediment bed will armor.

6. Bed erodes away smoothly.

7. Model behaves reasonably for accumulation in the bed with no erosion.

Additional evaluation and testing were performed through application of the combined models to a prototype system: Lake George, Florida. The codes perform reasonably through a three-year simulation. The tests indicate, however, that realistic application of SEDZLJ requires an extensive set of field and laboratory observations.

DISCLAIMER: The contents of this report are not to be used for advertising, publication, or promotional purposes. Citation of trade names does not constitute an official endorsement or approval of the use of such commercial products. All product names and trademarks cited are the property of their respective owners. The findings of this report are not to be construed as an official Department of the Army position unless so designated by other authorized documents. 


\section{Contents}

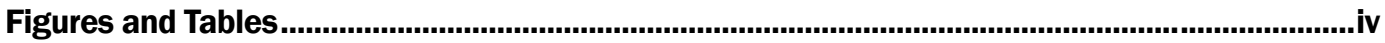

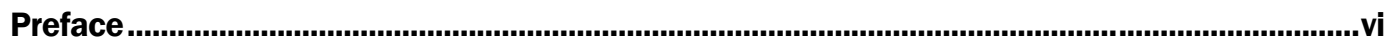

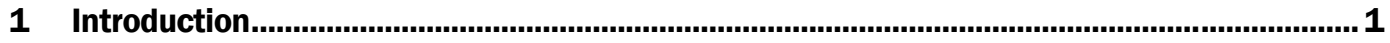

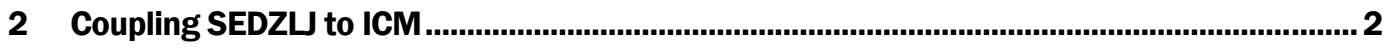

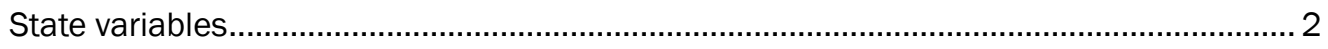

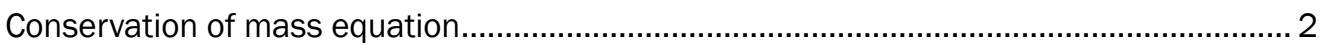

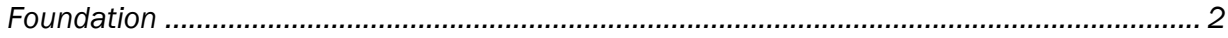

Deposition and erosion .............................................................................................. 4

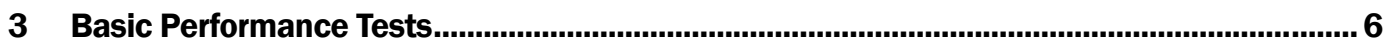

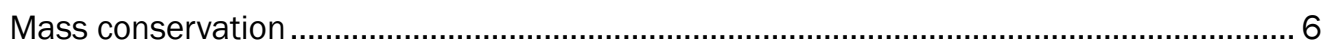

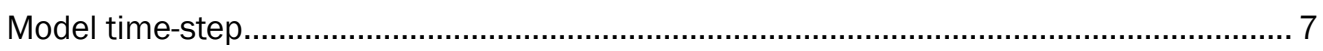

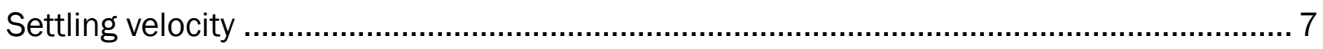

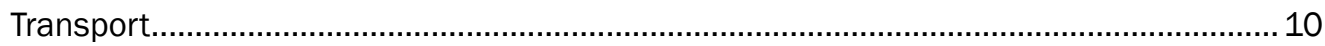

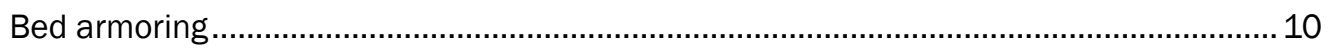

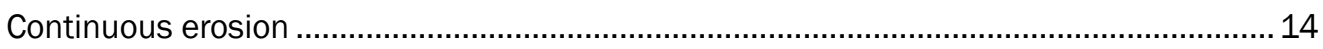

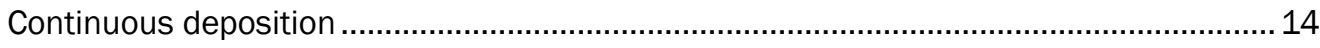

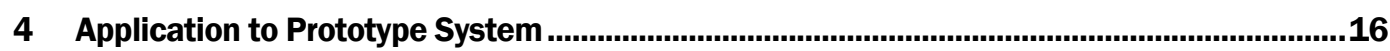

Lake George, Florida ............................................................................................... 16

Previous Lake George application ............................................................................. 19

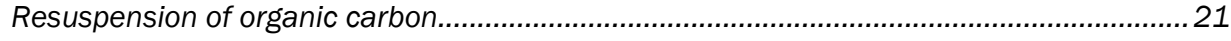

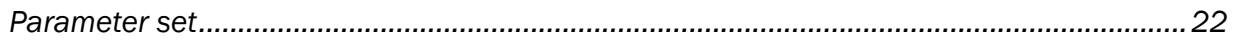

SEDZL application to Lake George ...................................................................... 23

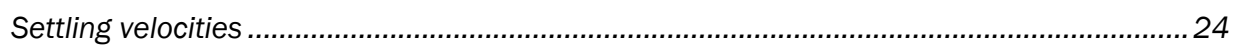

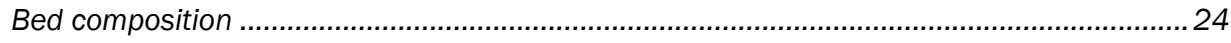

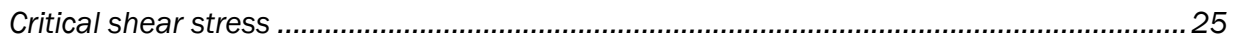

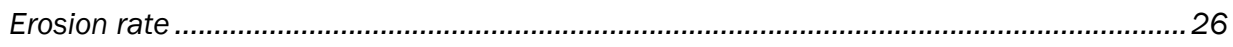

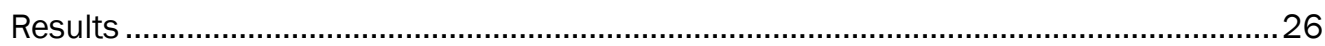

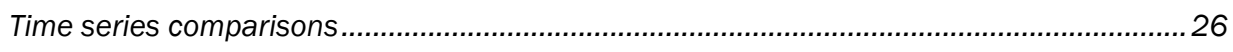

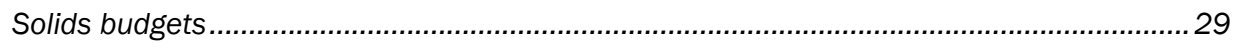

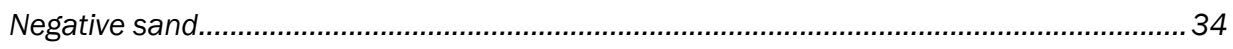

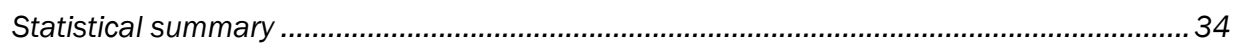

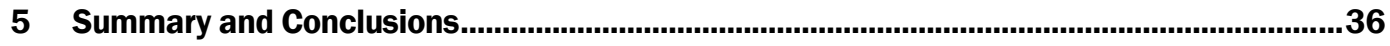

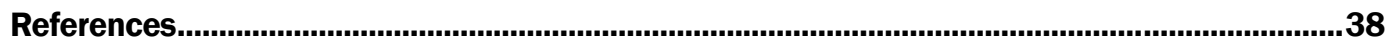

Report Documentation Page 


\section{Figures and Tables}

\section{Figures}

Figure 1. Elevation view of 30-box test grid. Cells are $30 \mathrm{~km}$ (length) x $20 \mathrm{~km}$ (width) x $5 \mathrm{~m}$ (height).

Figure 2. LPOC results from mass balance test. Initial and final concentrations are shown for three levels in the water column and for the surface bed layer. Results for RPOC are identical.

Figure 3. Clay/silt results from mass balance test. Initial and final concentrations are shown for three levels in the water column and for the surface bed layer.....

Figure 4. Fine sand results from mass balance test. Initial and final concentrations are shown for three levels in the water column and for the surface bed layer.....

Figure 5. Medium sand results from mass balance test. Initial and final concentrations are shown for three levels in the water column and for the surface bed layer.

Figure 6. Results from test of settling through the water column. At the end of a 30-day run, computed concentrations of fixed solids (original constituent), LPOC (modified constituent), and clay/silt (new constituent) are identical in three layers.

Figure 7. Results from test of bed armoring. Bed Layer 3 armors because the critical shear stress for erosion exceeds the imposed shear stress.

Figure 8. Results from test of bed armoring. Although imposed shear stress exceeds critical shear stress, bed Layer 2 does not erode. The probability of suspension for medium sand is low.

Figure 9. Results from test of continuous erosion. The upper four bed layers erode immediately. The bottom layer erodes continuously for 30 days.

Figure 10. Results from test of continuous deposition. The surface bed layer accumulates material continuously. No new layer is added to accommodate the additional material.

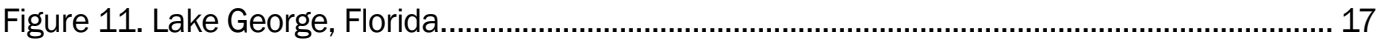

Figure 12. Computed velocity-generated bottom shear stress in the northern neck of Lake George.

Figure 13. Computed velocity-generated bottom shear stress in the open lake.

Figure 14. Computed velocity-generated bottom shear stress in the southern "tail" of Lake George.

Figure 15. Observed wind and computed bottom shear stress from two sources, wind waves and currents, in the open lake, January 1997.

Figure 16. Computational grid superimposed on an aerial photo of Lake George and surroundings. The lengthy passage ("neck" at top) to the lower St. Johns River is included in the grid as is a small portion of the major lake inflow ("tail" at bottom).

Figure 17. Lake George sample stations.

Figure 18. Computed and observed TSS at station MSJLGM for two suspended solids models, SEDZL and an "old" model based on long-term equilibrium between deposition and resuspension. 
Figure 19. Computed fixed solids at station MSJLGM for two suspended solids models, SEDZU and an "old" model based on long-term equilibrium between deposition and resuspension.

Figure 20. Computed and observed POC at station MSJLGM for two suspended solids models, SEDZ $\sqcup$ and an "old" model based on long-term equilibrium between deposition and resuspension

Figure 21. Computed individual sediment components from SEDZL at station MSJLGM. 30

Figure 22. Computed and observed TSS at station MSJFGF for two suspended solids models, SEDZ $\sqcup$ and an "old" model based on long-term equilibrium between deposition and resuspension.

Figure 23. Computed and observed TSS at station LG12 for two suspended solids models, SEDZ $J$ and an "old" model based on long-term equilibrium between deposition and resuspension

Figure 24. Computed and observed TSS at station MSJLGS for two suspended solids models, SEDZ $\sqcup$ and an "old" model based on long-term equilibrium between deposition and resuspension

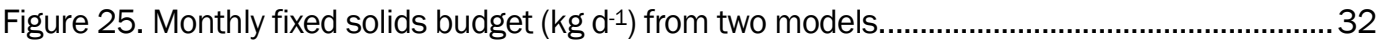

Figure 26. Monthly POC budgets ( $\mathrm{kg} \mathrm{d}^{-1}$ ) from two models. .........................................................33

\section{Tables}

Table 1. Mass conservation and sensitivity to time-step test results. Concentrations $\left(\mathrm{g} \mathrm{m}^{-2}\right)$ are presented for a single column of water and sediment cells.

Table 2. Transport test results. Concentrations are presented for each cell in the 30-box test grid (Figure 1) after a 30-day model run.

Table 3. Parameter set from previous model application.

Table 4. Particle diameters and settling velocities for SEDZU application.

Table 5. Initial bed characteristics for SEDZL application.

Table 6. Critical shear stress for erosion, SEDZL application.

Table 7. Solids budgets for two models, averaged over the simulation period.

Table 8. Statistical summary of computations from two models. 


\section{Preface}

The work described in this report was funded by the Dredging Operations and Environmental Research (DOER) Program. Dr. Todd Bridges is Program manager of DOER. The work was conducted under the direct supervision of Dr. Quan Dong, Chief, Water Quality and Contaminant Modeling Branch, Environmental Laboratory (EL), US Army Engineer Research and Development Center (ERDC), Vicksburg, MS.

This report was prepared by Dr. Carl F. Cerco of the Water Quality and Contaminant Modeling Branch, EL, ERDC. At the time of publication of this report, Dr. Beth Fleming was Director of EL.

At the time of publication COL Kevin J. Wilson was Commander of ERDC. Dr. Jeffery P. Holland was Director. 


\section{Introduction}

This report describes the merger of the SEDZLJ sediment transport model with the U.S. Army Corps of Engineers' CE-QUAL-ICM (or simply ICM) water quality model. The merger of ICM with SEDZLJ is the first step in the development of a high-fidelity contaminant transport and fate model based on the ICM concept and formulations. The sediment transport model is necessary because contaminants commonly partition to sediments of various compositions and are therefore transported along with the sediments. Burial in bottom sediments provides one pathway by which contaminants leave a system. Quantification of this removal requires knowledge of long-term sediment erosion and deposition rates. The coupling of the sediment transport model with ICM takes advantage of the detailed ICM representation of the aquatic carbon cycle in the water column and bed sediments, which is necessary since hydrophobic contaminants display a strong tendency to adhere to organic carbon particles.

Numerous sediment transport models exist (Warner et al. 2008, Jones and Lick 2001, Tetra Tech Inc. 2007) and there was no need to develop a new one for this application. SEDZLJ was selected because of its previous use in contaminant fate and transport studies (e.g. Weston Solutions Inc. 2006), because Corps personnel have experience with the code and formulations, and because the model is readily parameterized using results from the Corps' SEDFLUME device.

Anchor QEA LLC, Montvale, New Jersey, was contracted to merge the SEDZLJ code into ICM. Personnel at the U.S. Army Engineer Research and Development Center (ERDC) performed quality assurance checks on the merger and completed the coupling of SEDZLJ with various facets of ICM. This report describes the coupling of the two models, basic performance testing, and implementation of the merged models on a prototype system. 


\section{Coupling SEDZL to ICM}

\section{State variables}

Three new state variables were introduced to the ICM suite:

- Clay/Silt (Cohesive Sediment)

- Fine Sand (Non-cohesive Sediment)

- Medium Sand (Non-cohesive Sediment)

In addition, two existing ICM variables, labile particulate organic carbon (LPOC) and refractory particulate organic carbon (RPOC) were treated as discrete cohesive sediment particles. This treatment avoids the need to assign carbon fractions to mineral particles as in classic models of contaminant partitioning (Karickhoff et al. 1979). The incorporation of discrete carbon particles allows for the use of the full ICM carbon kinetics algorithms and allows for differential transport of carbon and mineral particles.

\section{Conservation of mass equation}

\section{Foundation}

The foundation of CE-QUAL-ICM is the solution to the three-dimensional mass-conservation equation for a control volume. Control volumes correspond to cells on the model grid. CE-QUAL-ICM solves, for each volume and for each state variable, the equation:

$$
\frac{\delta V_{j} \cdot C_{j}}{\delta t}=\sum_{k=1}^{n} Q_{k} \cdot C_{k}+\sum_{k=1}^{n} A_{k} \cdot D_{k} \cdot \frac{\delta C}{\delta x_{k}}+\Sigma S_{j}
$$

where

$$
\begin{aligned}
V_{j} & =\text { volume of } \mathrm{j}^{\text {th }} \text { control volume }\left(\mathrm{m}^{3}\right) \\
C_{j} & =\text { concentration in } \mathrm{j}^{\text {th }} \text { control volume }\left(\mathrm{g} \mathrm{m}^{-3}\right) \\
t, x & =\text { temporal and spatial coordinates } \\
n & =\text { number of flow faces attached to } \mathrm{j}^{\text {th }} \text { control volume } \\
Q_{k} & =\text { volumetric flow across flow face } \mathrm{k} \text { of } \mathrm{j}^{\text {th }} \text { control volume }\left(\mathrm{m}^{3} \mathrm{~s}^{-1}\right) \\
C_{k} & =\text { concentration in flow across face } \mathrm{k}\left(\mathrm{g} \mathrm{m}^{-3}\right)
\end{aligned}
$$




$$
\begin{aligned}
A_{k}= & \text { area of flow face } \mathrm{k}\left(\mathrm{m}^{2}\right) \\
D_{k}= & \text { diffusion coefficient at flow face } \mathrm{k}\left(\mathrm{m}^{2} \mathrm{~s}^{-1}\right) \\
S_{j}= & \text { external loads and internal sources and sinks in } \mathrm{j}^{\text {th }} \text { control } \\
& \text { volume }\left(\mathrm{g} \mathrm{s}^{-1}\right)
\end{aligned}
$$

For the sediment particles in the water column, the only internal source/sink is settling:

$$
S_{j}=-W s \cdot \frac{\delta}{\delta z} S S I
$$

where

$$
\begin{aligned}
W s & =\text { settling velocity }\left(\mathrm{m} \mathrm{d}^{-1}\right) \\
S S I & =\text { solids concentration }\left(\mathrm{g} \mathrm{m}^{-3}\right) \\
Z & =\text { vertical coordinate }(\mathrm{m})
\end{aligned}
$$

Settling velocity is computed by Cheng's formula (Cheng 1997):

$$
W s=\frac{v}{d} \cdot\left[\sqrt{25+1.2 \cdot d_{*}^{2}}-5\right]^{1.5}
$$

where

$$
\begin{aligned}
& v=\text { kinematic fluid viscosity }\left(\mathrm{cm}^{2} \mathrm{~s}^{-1}\right) \\
& d=\text { particle diameter }(\mathrm{cm})
\end{aligned}
$$

Parameter $d$ is non-dimensional particle diameter

$$
d_{*}=\left(\frac{\Delta \cdot g}{v^{2}}\right)^{0.33} \cdot d
$$

where

$$
g \text { = gravitational acceleration }\left(\mathrm{cm} \mathrm{s}^{-2}\right)
$$

and

$$
\Delta=\frac{\rho_{s}-\rho}{\rho}
$$


where

$$
\begin{aligned}
\rho_{s} & =\text { density of particle }\left(\mathrm{g} \mathrm{cm}^{-3}\right) \\
\rho & =\text { density of water }\left(\mathrm{g} \mathrm{cm}^{-3}\right)
\end{aligned}
$$

Settling velocity of carbon particles is a model input variable.

\section{Deposition and erosion}

The sediment source/sink term for ICM cells that intersect the bottom is modified to include deposition to and erosion from the bed:

$$
S_{j}=\frac{W s}{\Delta z} \cdot S S I_{u p}+\frac{E-D}{\Delta z}
$$

where

$$
\begin{aligned}
S S I_{u p} & =\text { solids concentration in cell overlying cell } \mathrm{j}\left(\mathrm{g} \mathrm{cm}^{-3}\right) \\
E & =\text { erosion rate }\left(\mathrm{g} \mathrm{cm}^{2} \mathrm{~s}^{-1}\right) \\
D & =\text { deposition rate }\left(\mathrm{g} \mathrm{cm}^{2} \mathrm{~s}^{-1}\right) \\
\Delta z & =\text { cell thickness }(\mathrm{m})
\end{aligned}
$$

The erosion rate is determined by:

$$
E=f_{k} \cdot B D D \cdot S_{k} \cdot \text { Psus }_{k} \cdot \text { Egross }
$$

where

$$
\begin{aligned}
f_{k} & =\text { fraction of sediment class } \mathrm{k} \text { in active surface layer }\left(\mathrm{o}<\mathrm{f}_{\mathrm{k}}<1\right) \\
B D D & =\text { bed dry density }\left(\mathrm{g} \mathrm{cm}^{-3}\right) \\
S_{k} & =\text { particle shielding factor for sediment class } \mathrm{k}\left(\mathrm{o}<\mathrm{S}_{\mathrm{k}}<1\right) \\
\text { Psus } & =\text { probability of suspension for sediment class } \mathrm{k}\left(\mathrm{o}<\text { Psus }_{\mathrm{k}}<1\right) \\
\text { Egross } & =\text { gross erosion rate }\left(\mathrm{cm} \mathrm{s}^{-1}\right)
\end{aligned}
$$

The gross erosion rate is computed as:

$$
\begin{gathered}
\text { Egross }=A \cdot \tau_{s f}^{n} \quad \text { for } \tau_{s f}>\tau_{c r} \\
=0 \quad \text { for } \tau_{s f}<\tau_{c r}
\end{gathered}
$$


where

$$
\begin{aligned}
\tau_{s f} & =\text { bottom shear stress }\left(\text { dyne } \mathrm{cm}^{-2}\right) \\
\tau_{c r} & =\text { critical shear stress for erosion }\left(\text { dyne } \mathrm{cm}^{-2}\right) \\
A, n & =\text { empirical parameters }
\end{aligned}
$$

Particle shielding and probability of suspension are described in Jones and Lick (2001).

Deposition is computed:

$$
D=\operatorname{Pdep}_{k} \cdot W s_{k} \cdot S_{k}
$$

where

$$
\operatorname{Pdep}_{k}=\text { probability of deposition }\left(\mathrm{o}<\operatorname{Pdep}_{\mathrm{k}}<1\right)
$$

Probability of deposition is determined for cohesive and non-cohesive sediment classes as described by Jones and Lick (2001). 


\section{Basic Performance Tests}

Basic performance criteria were specified for acceptance of the merger of the SEDZLJ and ICM codes. The criteria were developed based on initial explorations of the linked models and included:

1. Mass conservation in water and bed.

2. Limited sensitivity to variations in model time-step.

3. Settling of new ICM state variables through model water column agrees with settling of original ICM state variables.

4. Transport of new ICM state variables agrees with transport of original ICM state variables.

5. Sediment bed will armor.

6. Bed erodes away smoothly.

7. Model behaves reasonably for accumulation in the bed with no erosion.

The explorations were conducted on a 30-box grid (Figure 1) developed as an ICM test bed. Geometry and circulation in the test system are roughly scaled to resemble the mainstem of Chesapeake Bay. The test bed provides the developer with maximum flexibility to examine model behavior via modifications to the ICM inputs and options installed in the ICM code.

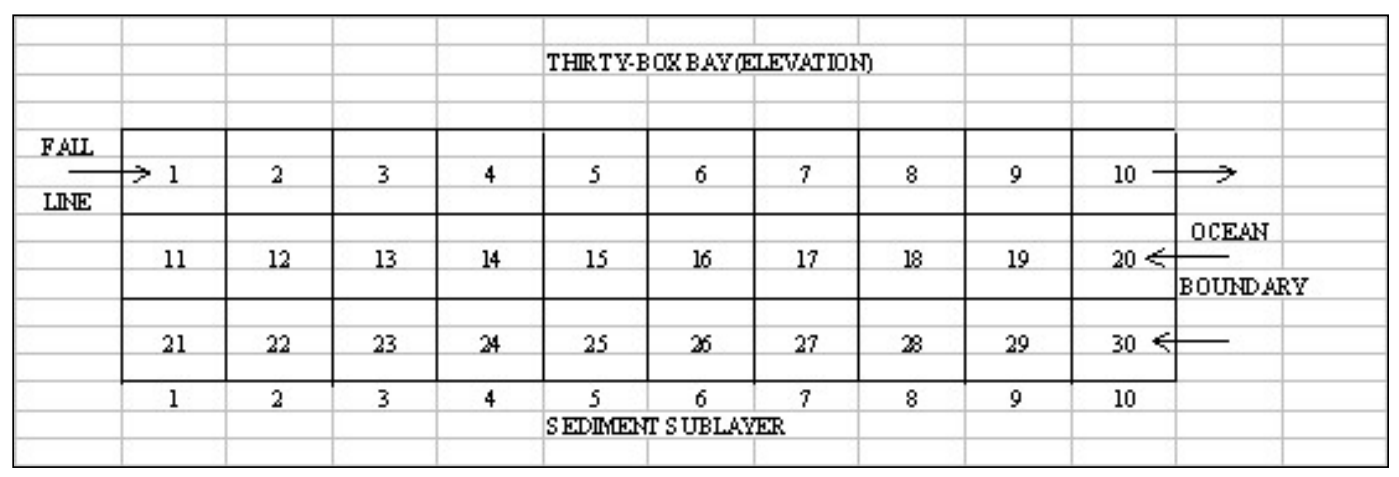

Figure 1. Elevation view of 30-box test grid. Cells are $30 \mathrm{~km}$ (length) $\times 20 \mathrm{~km}$ (width) $\times 5 \mathrm{~m}$ (height).

\section{Mass conservation}

For this test, horizontal transport was eliminated. Mass conservation was examined in columns consisting of three water cells and five sediment layers. Active processes included vertical diffusion, settling, erosion, and deposition. The time-step was $1000 \mathrm{~s}$ and the test duration was five days. 
Initial conditions were identical for all constituents and provided a uniform distribution in the water column.

Over the five-day period, the carbon components exhibited minimal settling through the water column (Figure 2). Concentration increased in the bottom water layer, however, due to erosion from the sediments. The clay/silt component exhibited noticeable settling through the water column, due to higher settling velocity, and increased concentration in the bottom water layer due to material settling from above and eroding from below (Figure 3). Fine sand settled completely out of the upper two water layers and collected in the bottom layer due to settling from above and erosion from below (Figure 4). Medium sand disappeared completely from the water and accumulated in the sediments (Figure 5). Roughly 0.06\% of the initial mass of each component was lost over the five-day period (432 time iterations, Table 1).

\section{Model time-step}

The mass conservation tests were repeated with two different time-steps: $250 \mathrm{~s}$ and $2000 \mathrm{~s}$. The model demonstrated no degenerate behavior or extreme sensitivity to the time-step (Table 1). Results were slightly different for each test with mass potentially lost or gained. Results suggested a loss of accuracy as the time-step was increased with the least error $(\approx 0.04 \%)$ at the 250-s step and the greatest error $(\approx 0.09 \%)$ at the 2000-s step. Accuracy was slightly less for medium sand, which had the greatest settling velocity, than for POC and clay/silt, which had the slowest settling velocities. The small mass gains or losses were attributed to numerical round-off error and were deemed acceptable.

\section{Settling velocity}

ICM treats particle settling as a term in the kinetics formulations and codes. To ensure that the settling of the new and modified constituents agreed with results from previously tested and validated code, the computed concentrations of clay/silt (new constituent) and LPOC (modified constituent) were compared to fixed solids (original ICM variable) under conditions of pure settling. This test used the same conditions as the mass balance test except erosion and deposition were eliminated. Settling velocity of the three particle types was set to $1.319 \mathrm{~m} \mathrm{~d}^{-1}$ and the run was executed for 10 days. At the end of the run, concentrations of fixed solids, LPOC, and clay/silt were identical (Figure 6). 


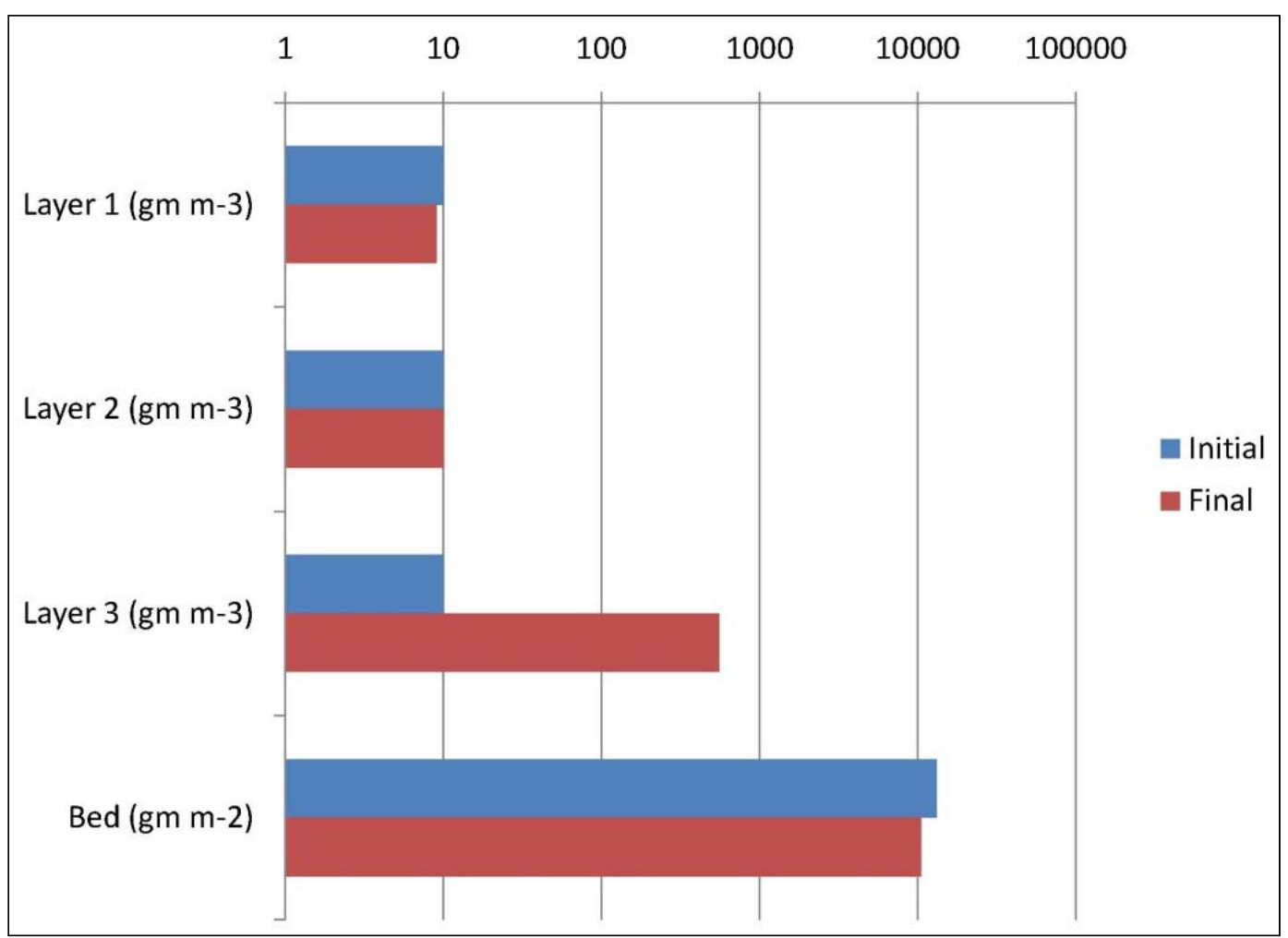

Figure 2. LPOC results from mass balance test. Initial and final concentrations are shown for three levels in the water column and for the surface bed layer. Results for RPOC are identical.

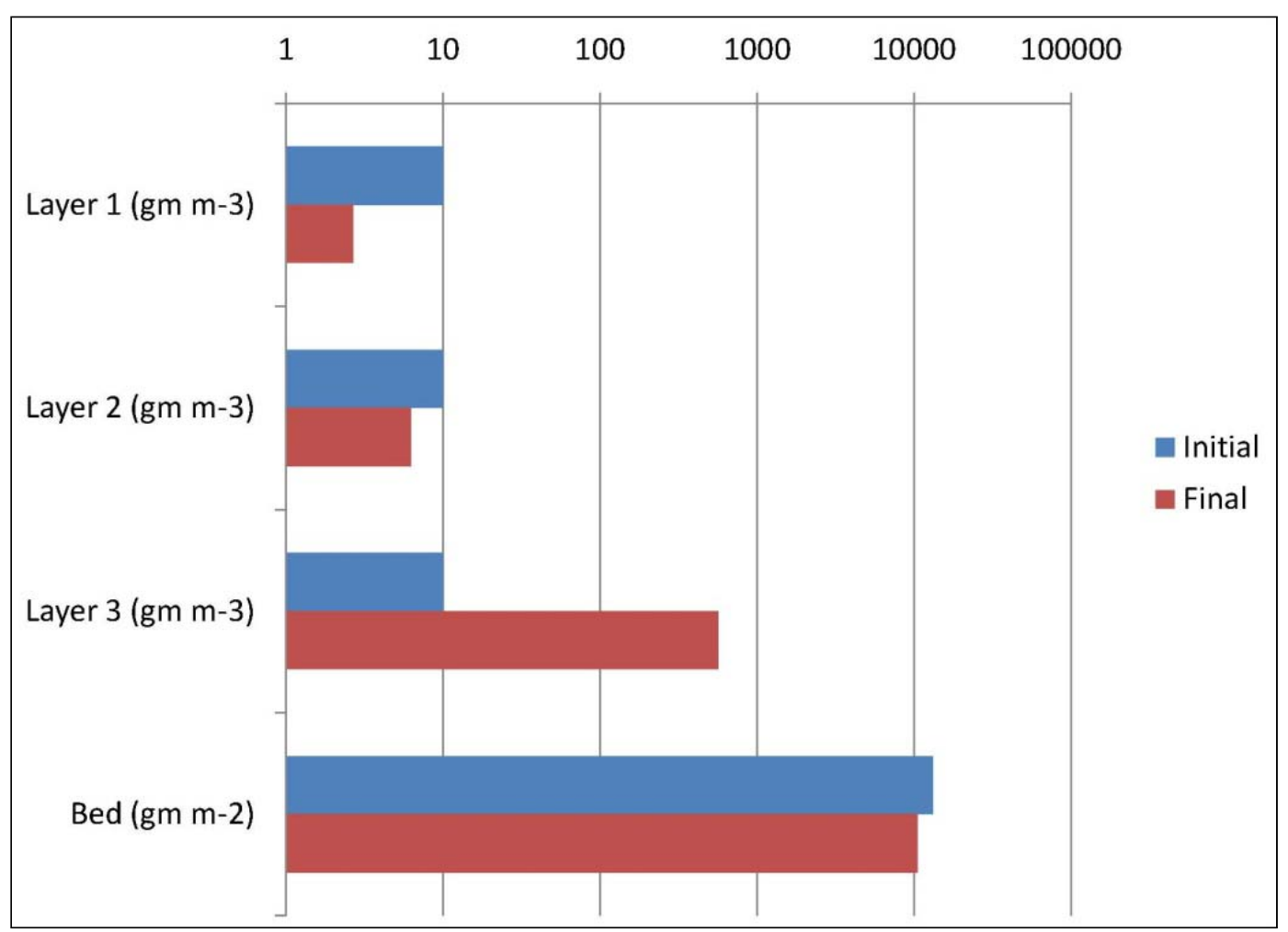

Figure 3. Clay/silt results from mass balance test. Initial and final concentrations are shown for three levels in the water column and for the surface bed layer. 


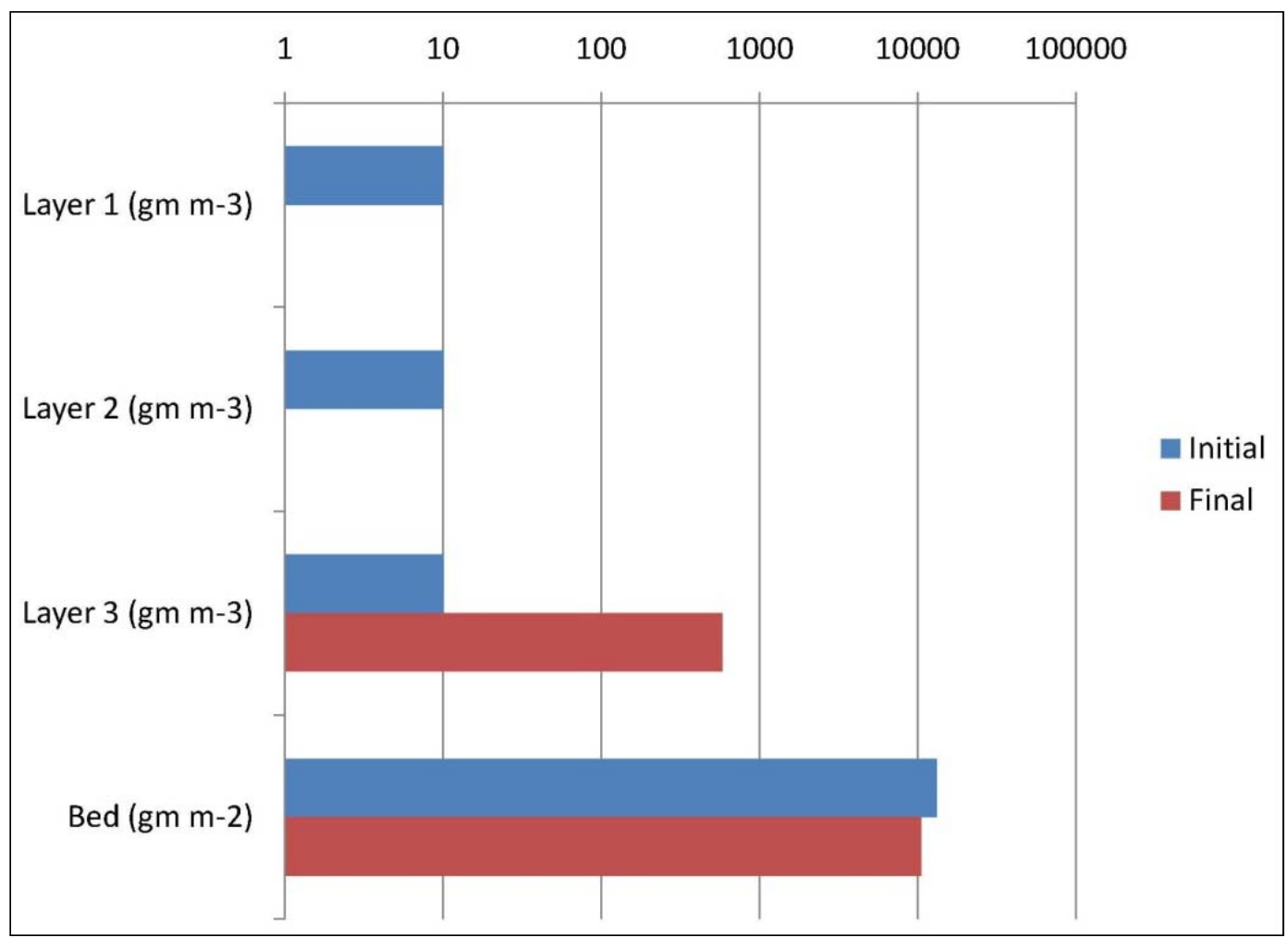

Figure 4. Fine sand results from mass balance test. Initial and final concentrations are shown for three levels in the water column and for the surface bed layer.

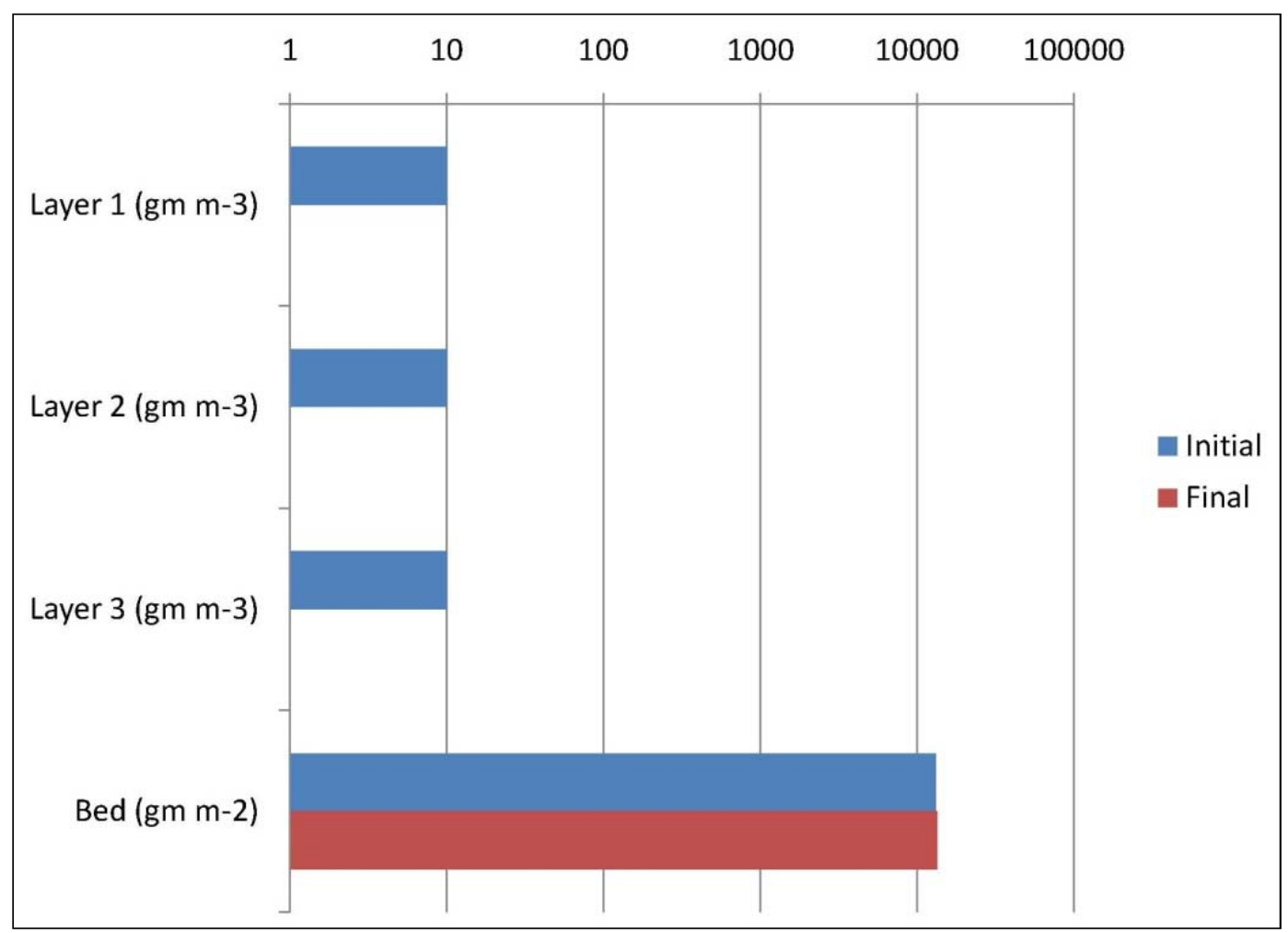

Figure 5. Medium sand results from mass balance test. Initial and final concentrations are shown for three levels in the water column and for the surface bed layer. 
Table 1. Mass conservation and sensitivity to time-step test results. Concentrations $\left(\mathrm{g} \mathrm{m}^{-2}\right)$ are presented for a single column of water and sediment cells.

\begin{tabular}{|l|l|l|l|l|}
\hline Variable & $\begin{array}{l}\text { Initial } \\
\text { Concentration }\end{array}$ & $\begin{array}{l}\text { Final } \\
\text { Concentration, } \\
\Delta \mathrm{t}=\mathbf{2 5 0 \mathrm { s }}\end{array}$ & $\begin{array}{l}\text { Final } \\
\text { Concentration, } \\
\Delta \mathrm{t}=1000 \mathrm{~s}\end{array}$ & $\begin{array}{l}\text { Final } \\
\text { Concentration, } \\
\Delta \mathrm{t}=\mathbf{2 0 0 0 \mathrm { s }}\end{array}$ \\
\hline LPOC, water & 150 & $2,857.45$ & $2,870.80$ & $2,861.50$ \\
\hline LPOC, sediments & 13,200 & $10,495.94$ & $10,471.40$ & $10,479.35$ \\
\hline LPOC, total & 31,350 & $13,353.39$ & $13,342.20$ & $13,340.90$ \\
\hline RPOC, water & 150 & $2,857.45$ & $2,870.80$ & $2,861.50$ \\
\hline RPOC, sediments & 13,200 & $10,495.94$ & $10,471.40$ & $10,479.35$ \\
\hline RPOC, total & 13,350 & $13,353.39$ & $13,342.20$ & $13,340.90$ \\
\hline Clay/Silt, water & 150 & $2,857.45$ & $2,870.85$ & $2,861.55$ \\
\hline Clay/Silt, sediments & 13,200 & $10,495.94$ & $10,471.40$ & 10.479 .35 \\
\hline Clay/Silt, total & 13,350 & $13,353.39$ & $13,342.25$ & $13,340.90$ \\
\hline Fine Sand, water & 150 & $2,907.55$ & $2,906.75$ & $2,826.40$ \\
\hline Fine Sand, sediments & 13,200 & 10.446 .17 & $10,438.32$ & $10,518.06$ \\
\hline Fine Sand, total & 13,350 & $13,353.72$ & $13,345.07$ & $13,344.46$ \\
\hline Medium Sand, water & 150 & 0.00 & 0.00 & 0.00 \\
\hline Medium Sand, sediments & 13,200 & $13,354.95$ & $13,341.80$ & $13,338.36$ \\
\hline Medium Sand, total & 13,350 & $13,354.95$ & $13,341.80$ & $13,338.36$ \\
\hline
\end{tabular}

\section{Transport}

One of the goals of this research was to ensure that transport of new and modified variables agreed with previously tested and validated code. This test was similar to the test of settling except that two-dimensional circulation similar to long-term average circulation in Chesapeake Bay was imposed. This run incorporated longitudinal and vertical currents, longitudinal and vertical diffusion, and vertical settling. At the end of a 10-day model run, computed concentrations of fixed solids, LPOC, and clay/silt were virtually identical (Table 2).

\section{Bed armoring}

Bed armoring was examined in two model runs that illustrated alternate mechanisms within the model. In the first run, critical shear stress for erosion was varied with depth into the bed. Critical stress was specified as 2 dyne $\mathrm{cm}^{-2}$ in the upper two layers of a five-layer bed. Critical stress was 12 dyne $\mathrm{cm}^{-2}$ in the remaining layers. A constant shear stress of 10 dyne $\mathrm{cm}^{-2}$ 


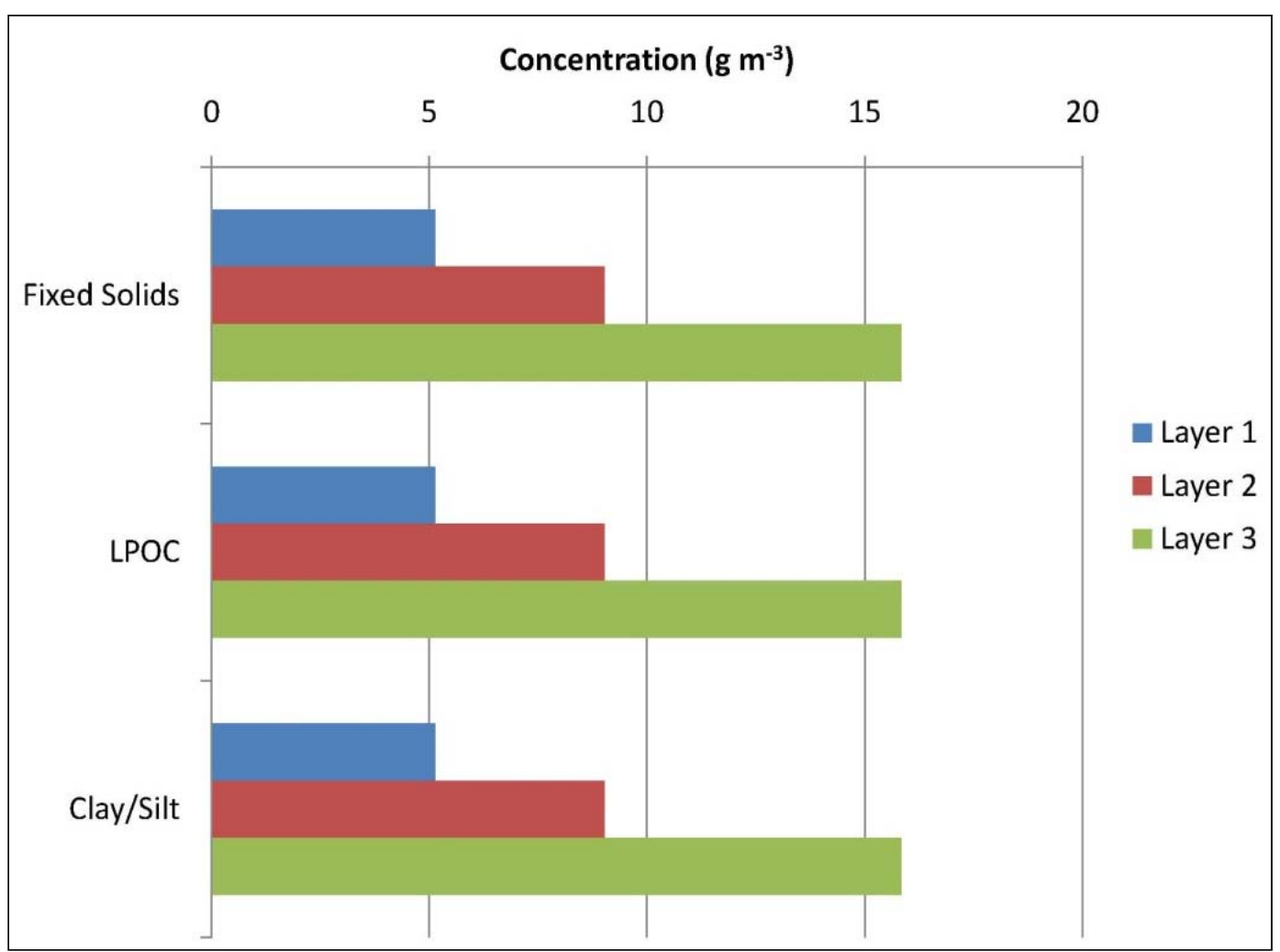

Figure 6. Results from test of settling through the water column. At the end of a 30-day run, computed concentrations of fixed solids (original constituent), LPOC (modified constituent), and clay/silt (new constituent) are identical in three layers.

Table 2. Transport test results. Concentrations are presented for each cell in the 30-box test grid (Figure 1) after a 30-day model run.

\begin{tabular}{|c|c|c|c|c|c|c|c|c|c|}
\hline \multicolumn{10}{|c|}{ Fixed Solids $\left(\mathrm{g} \mathrm{m}^{-3}\right)$} \\
\hline 6.1252 & 5.5968 & 5.5136 & 5.4992 & 5.4958 & 5.4882 & 5.4442 & 5.2479 & 4.6358 & 3.3559 \\
\hline 10.155 & 9.6632 & 9.5972 & 9.5871 & 9.5826 & 9.5582 & 9.4182 & 8.8444 & 7.2296 & 4.2711 \\
\hline 17.3246 & 16.7359 & 16.6663 & 16.6566 & 16.6492 & 16.5994 & 16.3146 & 15.167 & 12.0135 & 6.4678 \\
\hline \multicolumn{10}{|c|}{ LPOC $\left(\mathrm{g} \mathrm{m}^{-3}\right)$} \\
\hline 6.1252 & 5.5968 & 5.5136 & 5.4992 & 5.4958 & 5.4882 & 5.4442 & 5.2479 & 4.6358 & 3.3559 \\
\hline 10.155 & 9.6632 & 9.5972 & 9.5871 & 9.5826 & 9.5582 & 9.4182 & 8.8444 & 7.2296 & 4.2711 \\
\hline 17.3246 & 16.7359 & 16.6663 & 16.6566 & 16.6492 & 16.5994 & 16.3146 & 15.167 & 12.0135 & 6.4678 \\
\hline \multicolumn{10}{|c|}{ Clay/Silt ( $\left.\mathrm{g} \mathrm{m}^{-3}\right)$} \\
\hline 6.12 & 5.6 & 5.51 & 5.5 & 5.49 & 5.49 & 5.44 & 5.25 & 4.63 & 3.35 \\
\hline 10.15 & 9.66 & 9.6 & 9.59 & 9.58 & 9.56 & 9.42 & 8.84 & 7.23 & 4.27 \\
\hline 17.33 & 16.74 & 16.67 & 16.66 & 16.65 & 16.6 & 16.32 & 15.17 & 12.02 & 6.47 \\
\hline
\end{tabular}


was imposed. The bed was initiated with $20 \%$ of each particulate component and the water column was initiated with zero suspended particles. Two-dimensional circulation was imposed and the model was run for 30 days.

The upper layer $(5 \mathrm{~cm})$ of the bed eroded into the water column immediately (Figure 7). Although the gross erosion rate in the second layer was identical to the first layer, a portion of the previously eroded material simultaneously settled so that net erosion (erosion - deposition) slowed and the second layer took much longer than the first to disappear. Erosion ceased after the upper two layers disappeared and the imposed stress no longer exceeded the critical shear stress for erosion; the bed armored. An unexpected result was the subsequent accumulation of material in Layer 3. Material settling into Layer 3, now at the bed surface, acquired the properties of Layer 3, notably critical shear stress. The thickness of this layer increased from 5 to nearly $7 \mathrm{~cm}$ as material accumulated; Layer 2 was not restored to replace the layer that previously disappeared.

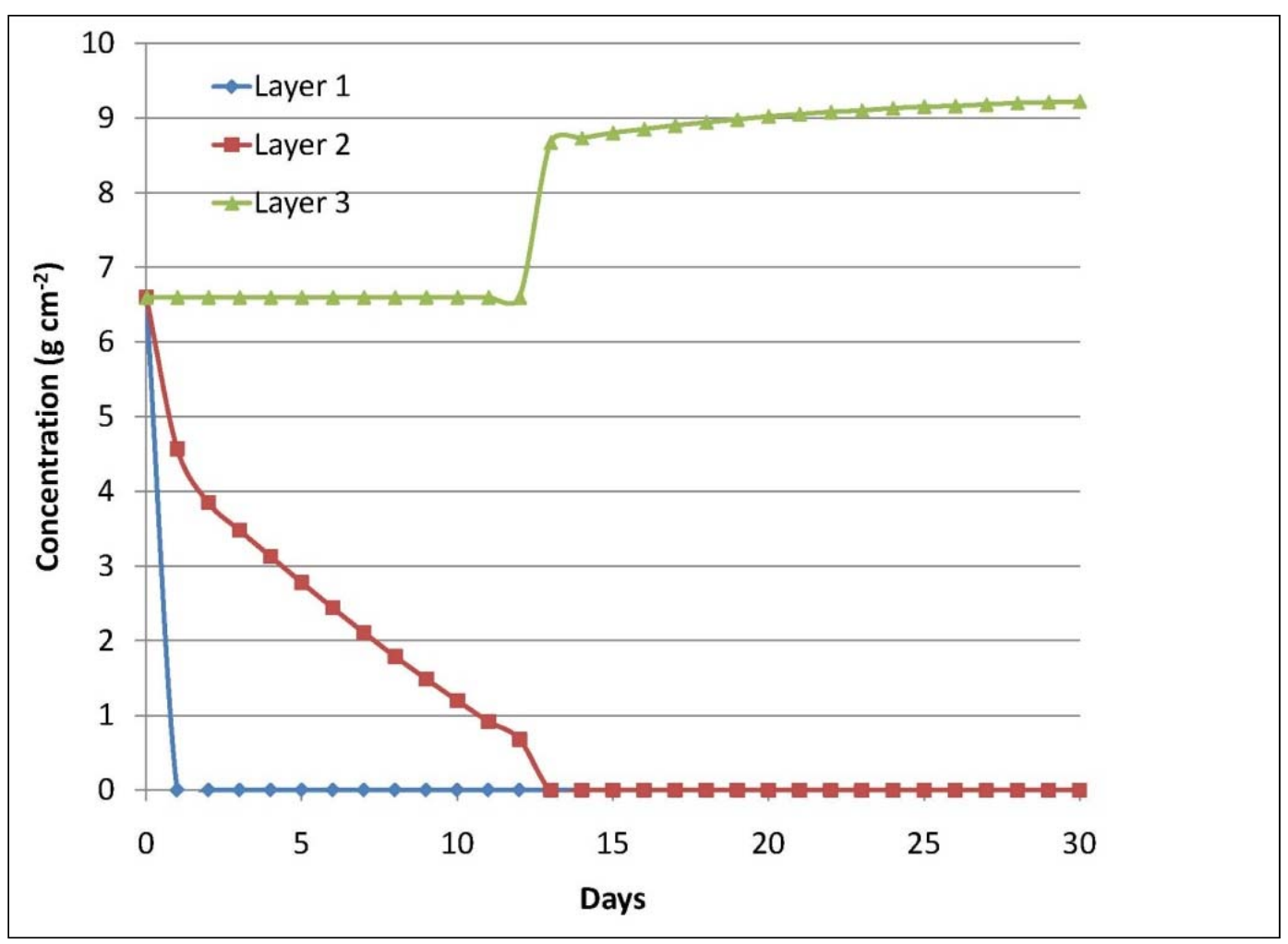

Figure 7. Results from test of bed armoring. Bed Layer 3 armors because the critical shear stress for erosion exceeds the imposed shear stress. 
In a subsequent test, initial conditions in the bed were varied. The uppermost layer was initialized at $40 \%$ clay/silt, $40 \%$ fine sand, and $20 \%$ medium sand (no LPOC or RPOC). The second layer was initialized at $10 \%$ clay/silt, 10\% fine sand, and 80\% medium sand. All layers below the upper two were split evenly into five components. The vertical distribution of critical shear stress and the imposed shear stress were retained from the first test. As with the first test, the upper-most sediment layer rapidly eroded into the water column (Figure 8). Erosion of the second layer, however, was significantly slower than in the first test. In fact, previously eroded material accumulated in Layer 2. Subsequent erosion of Layer 2 approached zero despite the excess of imposed stress, 10 dyne $\mathrm{cm}^{-2}$, over critical shear stress, 2 dyne $\mathrm{cm}^{-2}$. In this case, the bed armored because it consisted primarily of coarse heavy material with a low probability of suspension. The initially small fractions of fine material decreased, causing the fraction of medium sand to increase from $80 \%$, at the initiation of the run, to $88 \%$ at the end. Both of these tests indicated the SEDZLJ code provided acceptable representation of bed armoring.

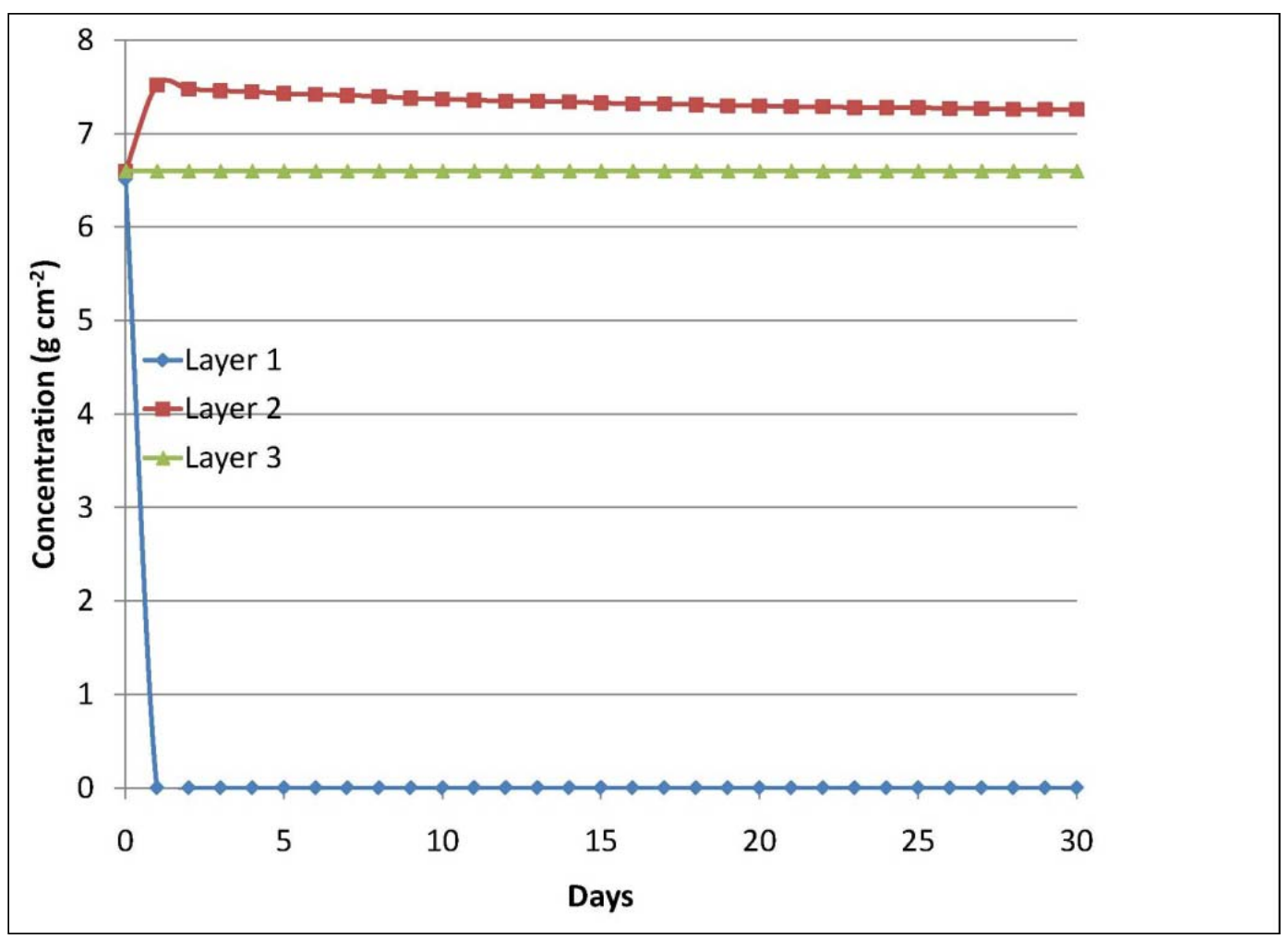

Figure 8. Results from test of bed armoring. Although imposed shear stress exceeds critical shear stress, bed Layer 2 does not erode. The probability of suspension for medium sand is low. 


\section{Continuous erosion}

For this test, a five-layer bed was set up. The upper four layers were $5 \mathrm{~cm}$ thick while the lowest layer was $80 \mathrm{~cm}$. Critical shear stress for erosion

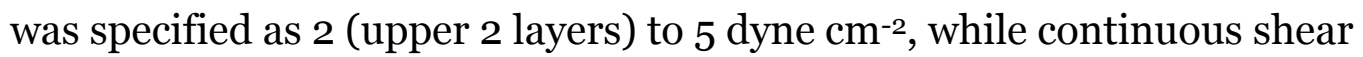
stress of 20 dyne $\mathrm{cm}^{-2}$ was imposed. The upper four layers eroded into the water column immediately. The bottom layer demonstrated continuous, smooth erosion for the duration of the 30-day run (Figure 9). This test demonstrated the ability of SEDZLJ to respond to erosion events by losing layers and by eroding continuously from a single layer.

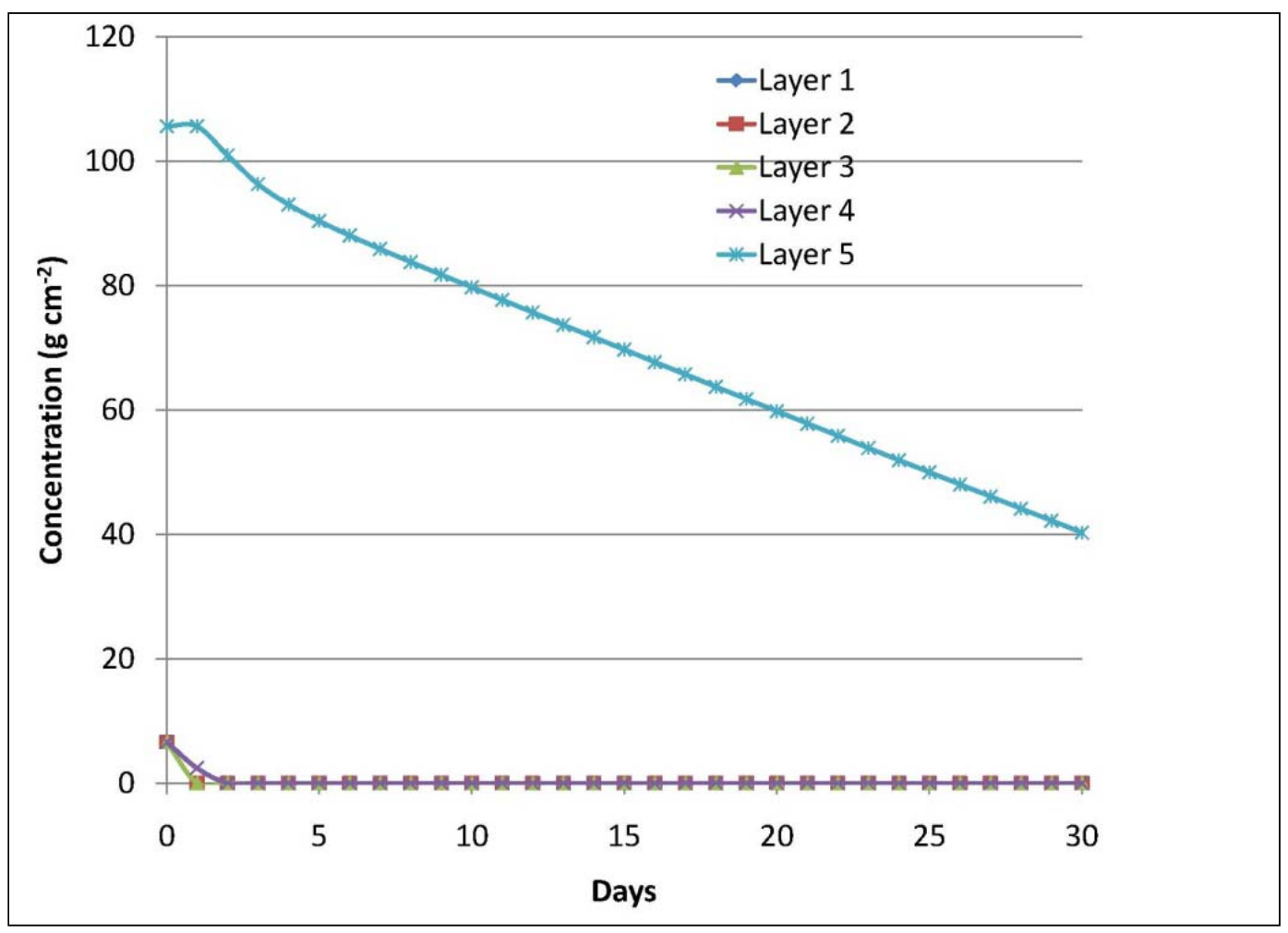

Figure 9. Results from test of continuous erosion. The upper four bed layers erode immediately. The bottom layer erodes continuously for 30 days.

\section{Continuous deposition}

For this test, shear stresses were specified so that erosion would not occur. Initial conditions and boundary conditions in the water column were specified to provide a large reservoir of material capable of settling. Twodimensional circulation was enabled and the model was run for 30 days. Material accumulated continuously in the surface sediment layer (Figure 10). By the end of the run, Layer 1 had increased in thickness from $5 \mathrm{~cm}$ to $189 \mathrm{~cm}$. This run demonstrated the ability of SEDZLJ to continuously 
accumulate material. This run also reinforced the findings from the tests of bed armoring; the thickness of the surface layer increased as material accumulated but no new layer was created despite the large amount of material deposited.

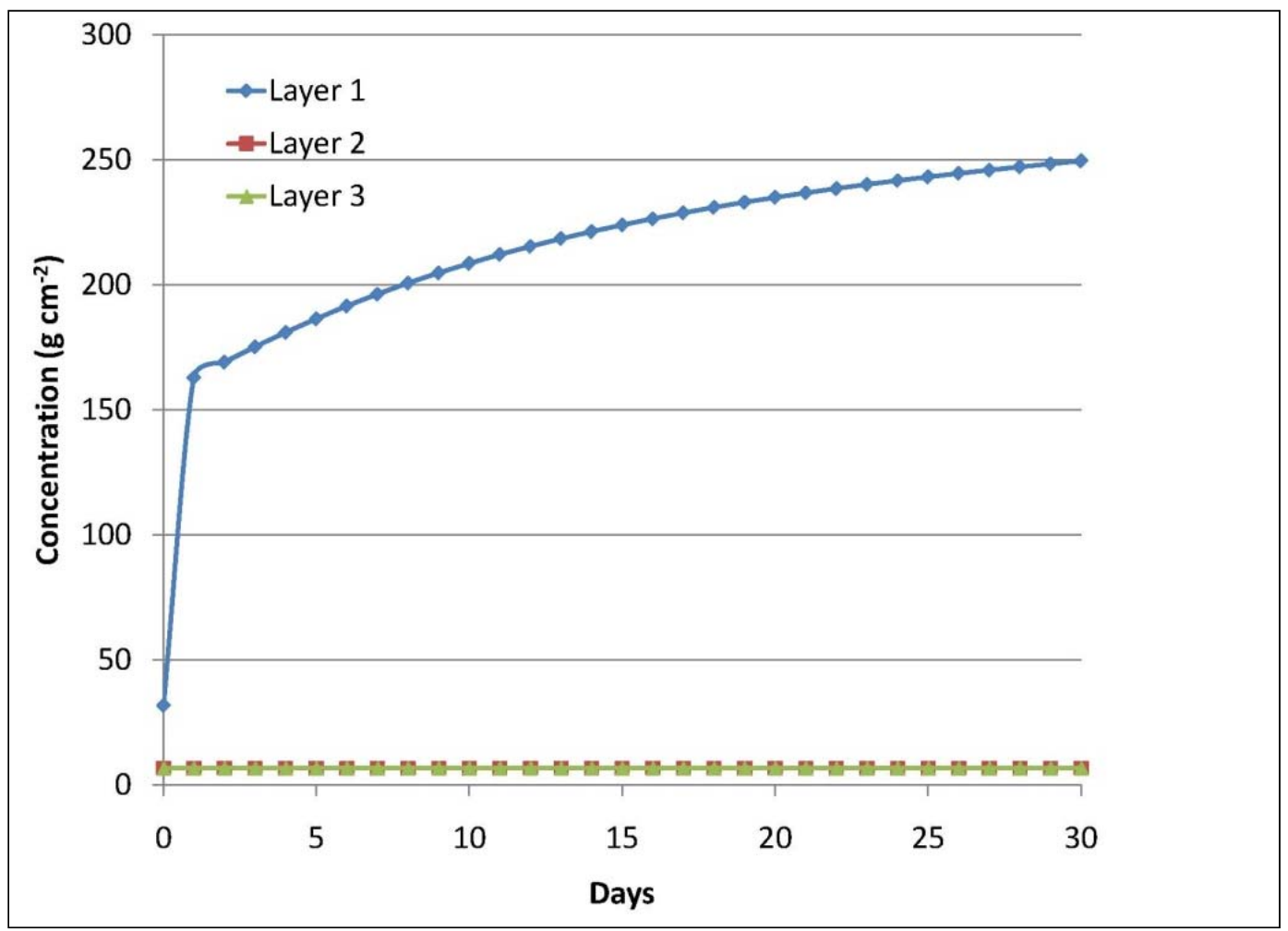

Figure 10. Results from test of continuous deposition. The surface bed layer accumulates material continuously. No new layer is added to accommodate the additional material. 


\section{Application to Prototype System}

\section{Lake George, Florida}

Additional testing of the code was gained through application of the combined ICM/SEDZLJ models to Lake George, Florida. This system was selected because it was the subject of a previous sediment transport application based on a different formulation. Application to Lake George facilitated testing of SEDZLJ, since forcing functions and several necessary parameter values were available. The previous application also provided a comparison for evaluating the capabilities and advantages of SEDZLJ.

Lake George is a shallow, freshwater lake (area $\approx 210 \mathrm{~km}^{2}$, average depth $\approx$ $3.1 \mathrm{~m}$ ) situated in northeast Florida at the head of the lower St. Johns River (Figure 11). Water leaves the lake through a forked passage at the northern end. Flow is primarily northwards, towards the St. Johns, but actions of wind and tide occasionally force water back from the St. Johns into Lake George. Lake George can be divided into three regions, based on computed currents and bottom stress. The first region is the long, narrow neck at the northern end that connects the lake with the lower St. Johns River. In this region, currents are primarily tidal and have a magnitude of $10 \mathrm{~cm} \mathrm{~s}^{-1}$. The second region is the open expanse of the lake itself. Currents in this section are also primarily tidal but an order of magnitude less than in the northern neck. The third region is the tail at the lower end that connects the lake to the upper St. Johns River. In this tail, the tidal signal is absent, currents are primarily riverine, and vary widely in magnitude. Velocity-generated bottom shear stresses, which are proportional to velocity squared, reflect and exaggerate the current regimes. In the northern neck, shear stresses are

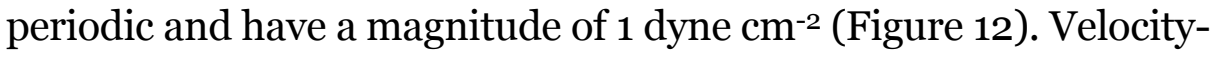
generated stresses are periodic in the open lake as well, but are one to two orders of magnitude less than in the northern neck (Figure 13). In the tail, velocity-generated stresses vary over orders of magnitude and are, during flow events, the largest in the system (Figure 14). In the open lake, bottom stress is exerted primarily by wind-generated waves (Figure 15) while in the narrow, convoluted, neck and tail, fetch is limited such that wind-generated stress on the bottom is zero. At their largest, wind-generated stresses in the lake are much less than the velocity-generated stresses in the inlet and outlet. While algorithms exist for combining shear stresses generated by currents and wind, the disparity in the magnitudes of these forcing 


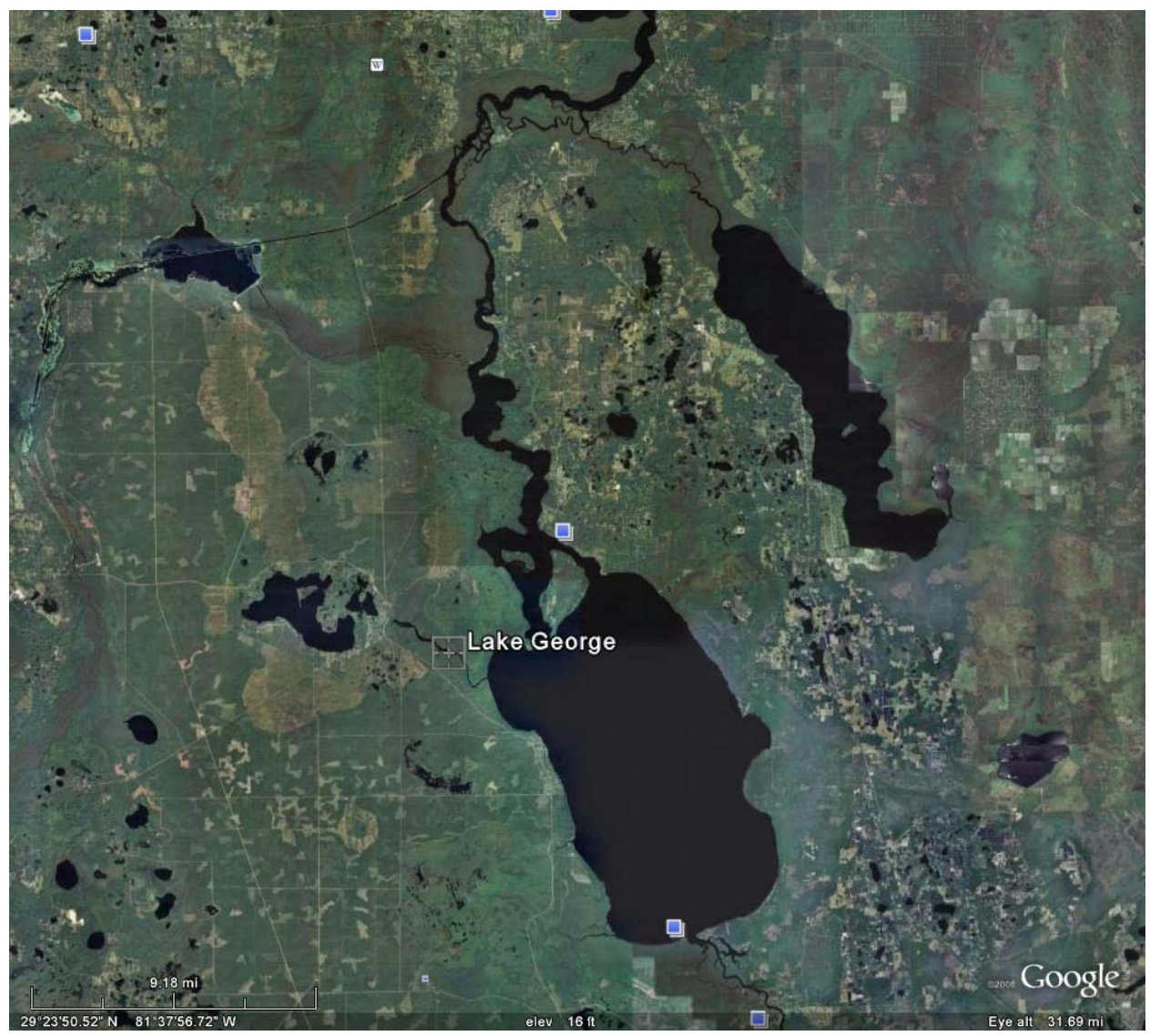

Figure 11. Lake George, Florida.

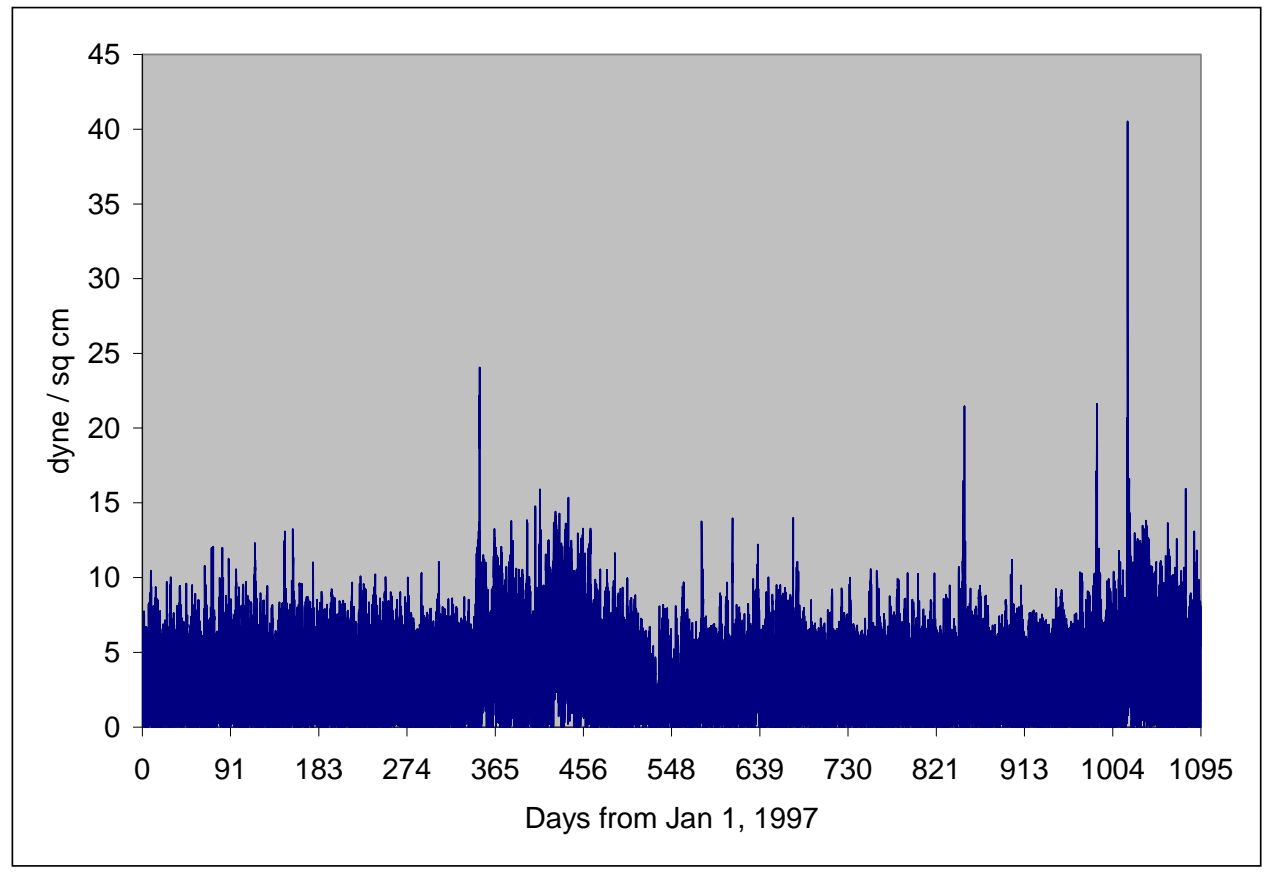

Figure 12. Computed velocity-generated bottom shear stress in the northern neck of Lake George. 


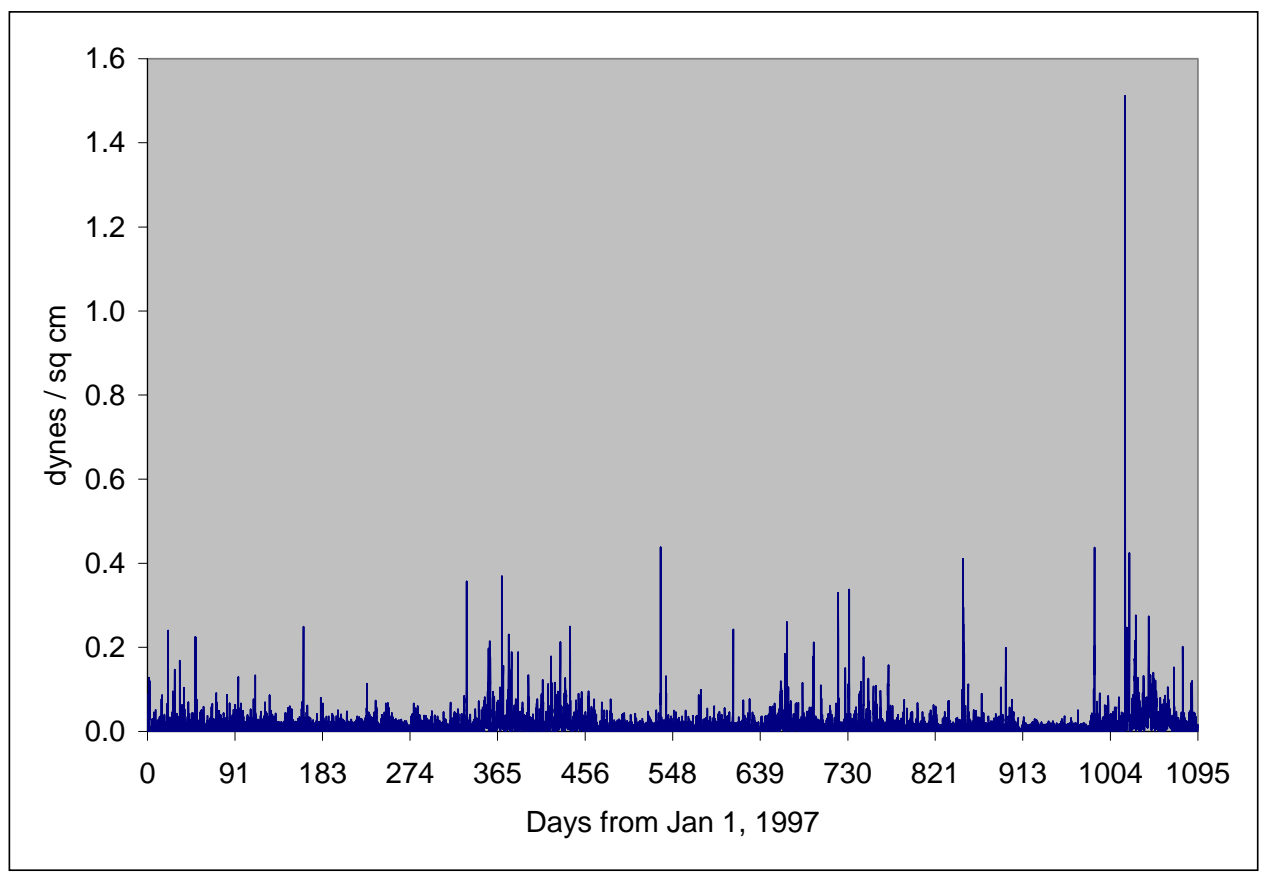

Figure 13. Computed velocity-generated bottom shear stress in the open lake.

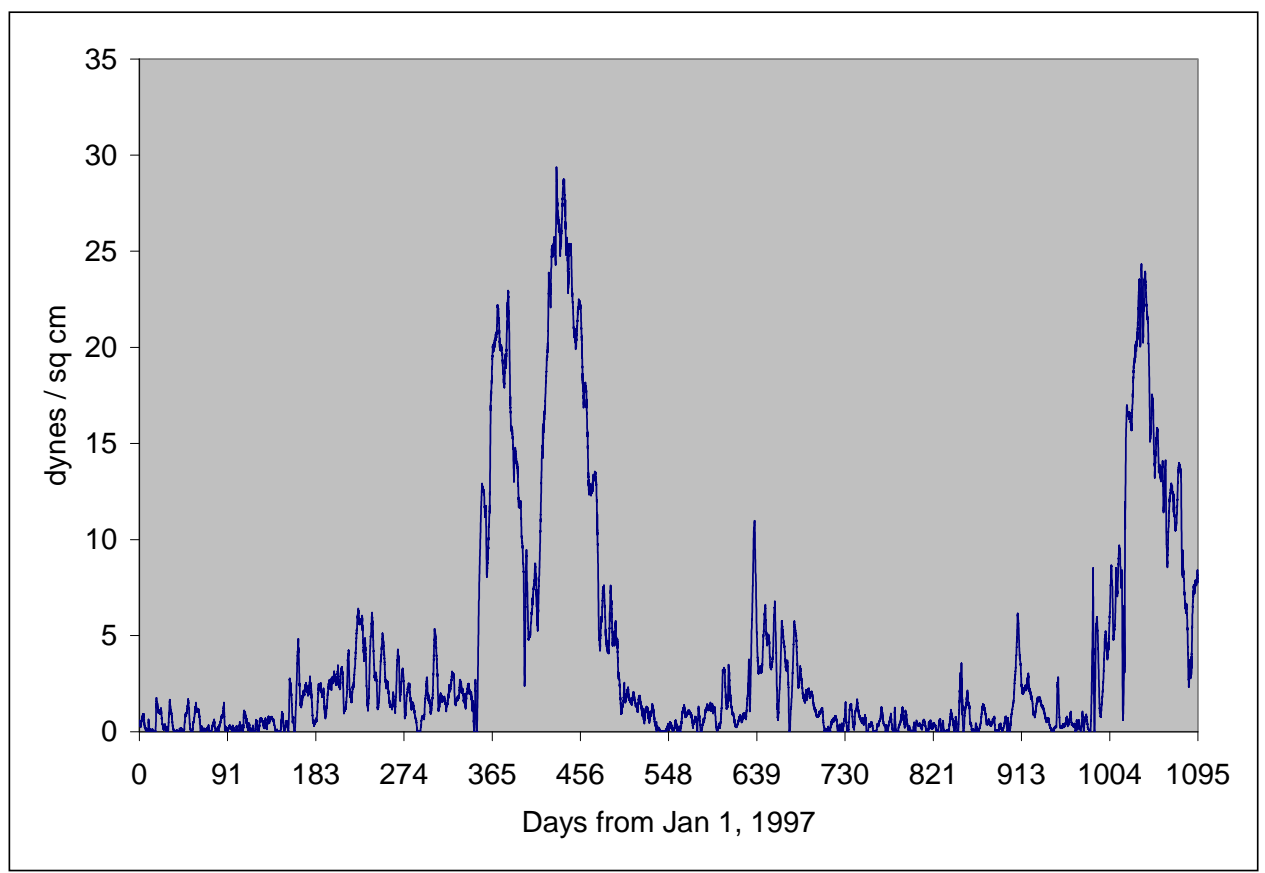

Figure 14. Computed velocity-generated bottom shear stress in the southern "tail" of Lake George. 


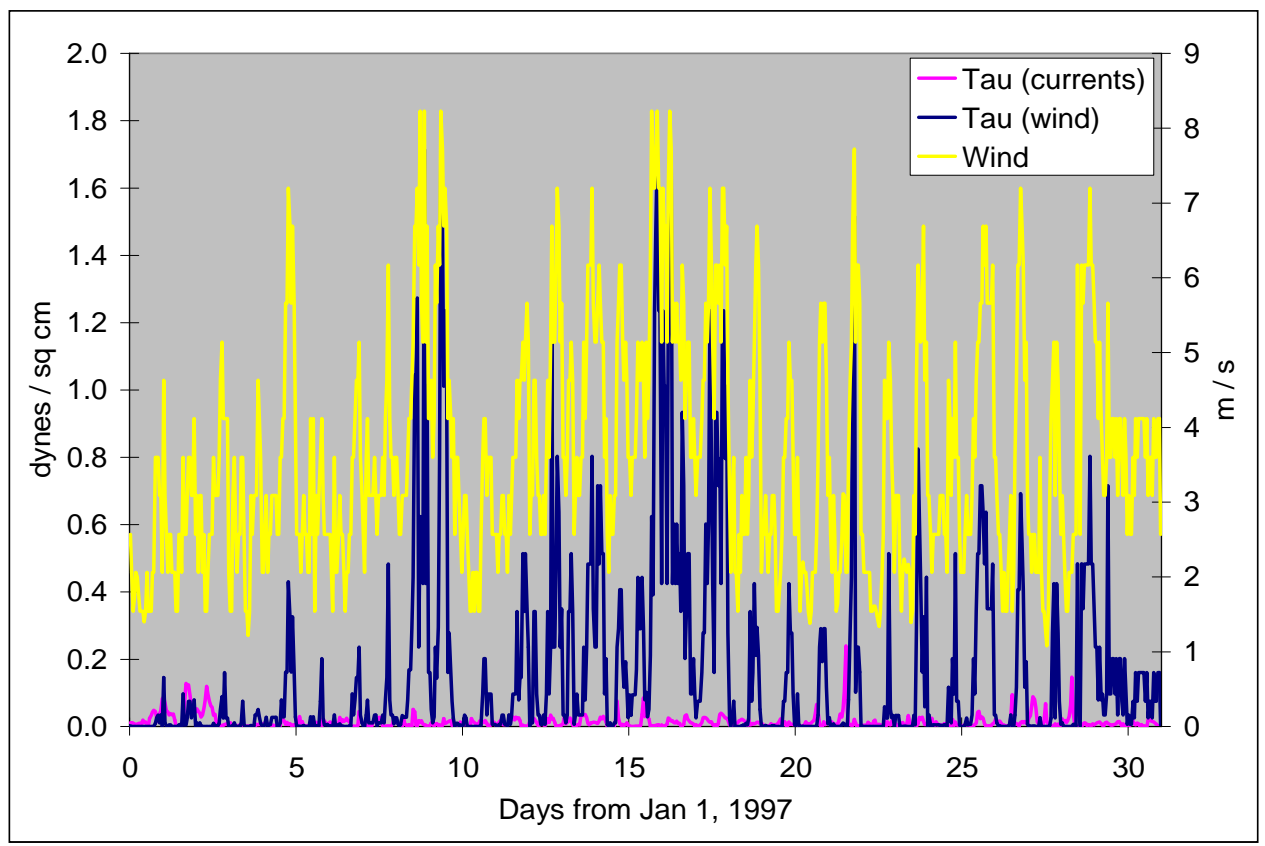

Figure 15. Observed wind and computed bottom shear stress from two sources, wind waves and currents, in the open lake, January 1997.

functions in the different regions of the lake leads to a simplifying assumption: shear stress in the neck and tail is derived exclusively from currents, while shear stress in the open lake is derived exclusively from waves.

The Lake George model operates on a three-dimensional grid consisting of 563 cells in the horizontal plane by two cells deep (Figure 16). CE-QUALICM treats each cell as a control volume and applies the three-dimensional mass-conservation equation with appropriate sources and sinks. The application period is three years, commencing on January 1, 1997.

\section{Previous Lake George application}

The previous Lake George application incorporated a complete eutrophication model (Cerco and Noel 2009) including algal production, nutrient cycling, and sediment diagenesis, as well as suspended solids. A single fixed solids class was considered. Computed particulate organic carbon was converted to volatile solids (VSS $=2.5 *$ POC) and combined with fixed solids for comparison with observed total suspended solids (TSS). Algorithms for computation of fixed solids followed Luettich et al. (1990), who modeled suspended sediments in a shallow lake perturbed by wind events. Settling and erosion, the sources and sinks for inorganic suspended solids, are represented by: 


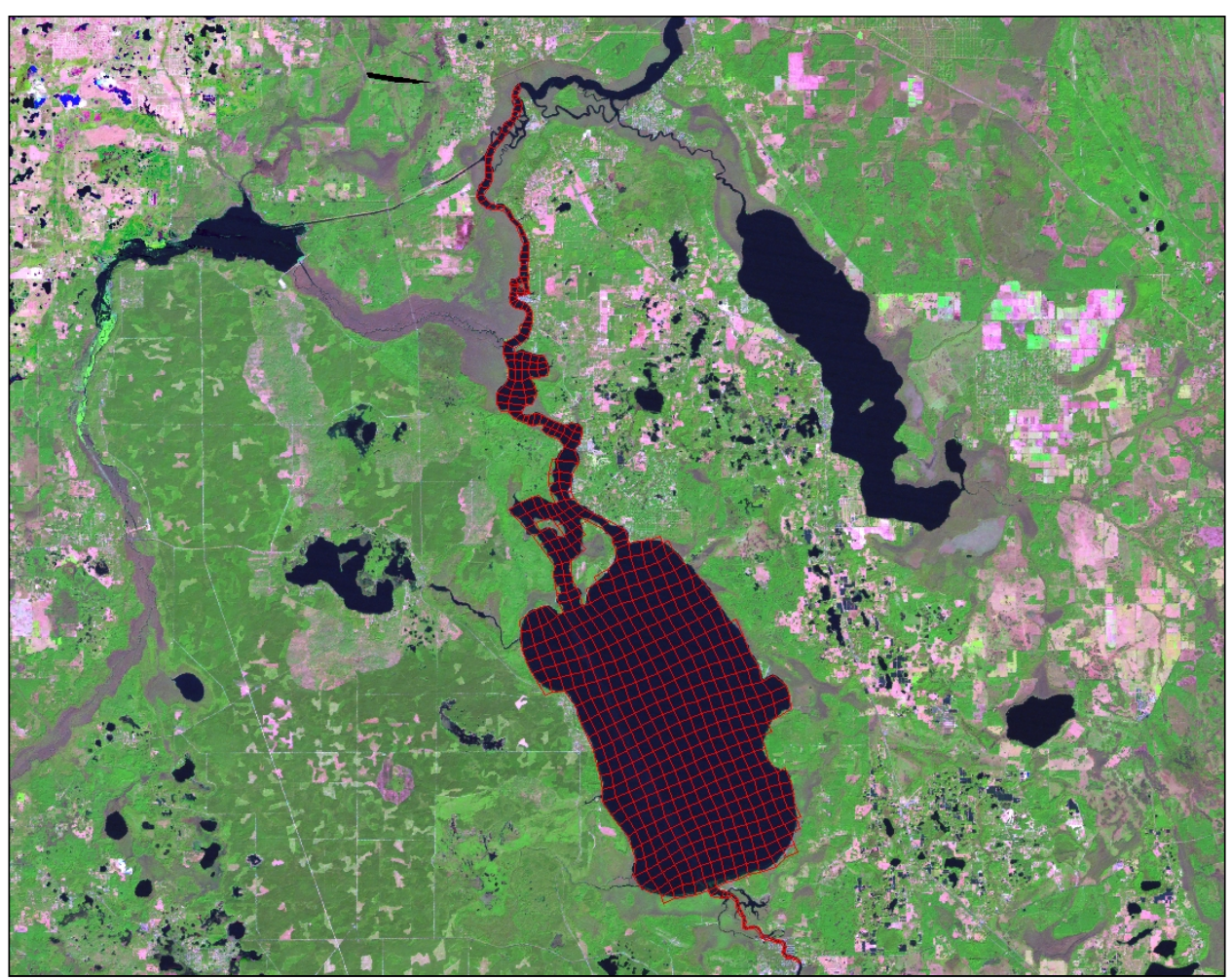

Figure 16. Computational grid superimposed on an aerial photo of Lake George and surroundings. The lengthy passage ("neck" at top) to the lower St. Johns River is included in the grid as is a small portion of the major lake inflow ("tail" at bottom).

$$
\frac{\delta C}{\delta t}=-w s \cdot \frac{\delta[C-C b]}{\delta z}+\left.\frac{E}{\Delta z}\right|_{z=d}
$$

where

$$
\begin{aligned}
C & =\text { inorganic suspended solids concentration }\left(\mathrm{g} \mathrm{m}^{-3}\right) \\
C b & =\text { background concentration }\left(\mathrm{g} \mathrm{m}^{-3}\right) \\
w s & =\text { settling velocity }\left(\mathrm{m} \mathrm{d}^{-1}\right) \\
E & =\text { erosion rate }\left(\mathrm{g} \mathrm{m}^{-2} \mathrm{~d}^{-1}\right) \\
\Delta z & =\text { thickness of grid cell adjoining bottom } \\
Z & =\text { vertical coordinate }(\mathrm{m}) \\
t & =\text { time }(\mathrm{d})
\end{aligned}
$$

The suspended solids model incorporates a background concentration of fine material, which does not settle.

The erosion term is applied only in cells adjoining the bottom $(\mathrm{z}=\mathrm{d})$ and is proportional to excess shear stress: 


$$
E=w s \cdot \operatorname{Cref} \cdot\left[\frac{\tau-\tau c}{\tau r e f}\right]^{n}
$$

where

$$
\begin{aligned}
\text { Cref } & =\text { reference concentration }\left(\mathrm{g} \mathrm{m}^{-3}\right) \\
\tau c & =\text { critical shear stress for erosion }\left(\text { dyne } \mathrm{cm}^{-2}\right) \\
\tau r e f & =\text { reference shear stress }\left(\text { dyne } \mathrm{cm}^{-2}\right) \\
n & =\text { exponent of order } 1
\end{aligned}
$$

The model is grounded on the assumption of long-term equilibrium between sediment deposition and resuspension; the bed solids concentration is effectively constant. Settling velocity is explicitly incorporated into the erosion term. This relationship necessarily accompanies the assumption of a constant bed mass. High settling velocity must be accompanied by high erosion rate, and vice-versa, or the bed would not be in equilibrium. The reference concentration is related to an equilibrium concentration that would be attained under conditions of constant excess $(\tau>\tau c)$ shear stress:

$$
\text { Ceq }=\text { Cref } \cdot\left[\frac{\tau-\tau c}{\tau r e f}\right]^{n}
$$

where

$$
C e q=\text { equilibrium suspended solids concentration }\left(\mathrm{g} \mathrm{m}^{-3}\right)
$$

In this model, solids continuously settle from the water into the bed; there is no critical shear stress for deposition.

\section{Resuspension of organic carbon}

As originally formulated, the representation of the sediment bed in the diagenetic model neglected resuspension. The mass balance (DiToro 2001) included net deposition from the water column, diagenesis (decay), and burial to deep, inactive, sediments:

$$
H \cdot \frac{d C s}{d t}=J-k \cdot H \cdot C s-w b \cdot C s
$$


in which

$$
\begin{aligned}
C s & =\text { concentration in sediment bed }\left(\mathrm{g} \mathrm{m}^{-3}\right) \\
H & =\text { depth of sediment bed }(\mathrm{m}) \\
J & =\text { net deposition rate }\left(=\text { wnet } \cdot \mathrm{C}, \mathrm{g} \mathrm{m}^{-2} \mathrm{~d}^{-1}\right) \\
k & =\text { diagenesis rate }\left(\mathrm{d}^{-1}\right) \\
w b & =\text { burial rate }\left(\mathrm{m} \mathrm{d}^{-1}\right)
\end{aligned}
$$

For Lake George, erosion was incorporated into the diagenetic sediment bed by defining a resuspension velocity:

$$
R=\frac{E s}{M s}
$$

where

$$
\begin{aligned}
R & =\text { resuspension velocity }\left(\mathrm{m} \mathrm{d}^{-1}\right) \\
E s & =\text { inorganic solids erosion rate }\left(\mathrm{g} \mathrm{m}^{-2} \mathrm{~d}^{-1}\right) \\
M s & =\text { inorganic solids concentration in bed }\left(\mathrm{g} \mathrm{m}^{-3}\right)
\end{aligned}
$$

One interpretation of the resuspension velocity is the rate of change of the bed thickness if the bed solids concentration remains constant. The mass balance for the bed then becomes:

$$
H \cdot \frac{d C s}{d t}=J-R \cdot C s-k \cdot H \cdot C s-w b \cdot C s
$$

and the erosional source to the water column is

$$
E=R \cdot C s
$$

Deposition is now represented by the settling through the water column, $w s$, rather than the previous net settling rate.

\section{Parameter set}

Parameters for the sediment resuspension algorithms were empirically derived. Initial values were input to the model and adjusted in subsequent model runs until satisfactory agreement was reached with observed solids data in the water column. This practice was consistent with parameter evaluation conducted in similar studies (Luettich et al. 1990; Bailey and 
Hamilton 1997; Hawley and Lesht 1992; James et al. 2004a, 2004b) and resulted in similar values (Table 3). Two key parameters in the resuspension algorithm were the critical shear stress for erosion $\tau c$ and the erosion potential (equivalent to the product of ws and Cref) $E$. The critical shear stress for the neck and tail was three times the value derived for the open lake, indicating the bottom sediments of the neck and tail are more resistant to erosion than the lake. The erosion potential of the lake was an order of magnitude higher than the neck and tail, representing a reservoir of fine, easily eroded material that is absent in the high-velocity regions.

Table 3. Parameter set from previous model application.

\begin{tabular}{|c|c|c|c|c|c|c|c|c|c|}
\hline \multirow[b]{2}{*}{ Lake } & \multirow[b]{2}{*}{ Location } & ws, & $\mathrm{Cb}$, & Cref, & $E$, & \multirow{2}{*}{$\begin{array}{l}\tau c \text {, dyne } \\
\mathrm{cm}^{-2}\end{array}$} & \multirow{2}{*}{$\begin{array}{l}\text { चref, } \\
\text { dyne } \\
\mathrm{cm}^{-2}\end{array}$} & \multirow[b]{2}{*}{$n$} & \multirow[b]{2}{*}{ Reference } \\
\hline & & $\mathrm{m} \mathrm{d}^{-1}$ & $\mathrm{~g} \mathrm{~m}^{-3}$ & $\mathrm{~g} \mathrm{~m}^{-3}$ & $\mathrm{~g} \mathrm{~m}^{-2} \mathrm{~d}^{-1}$ & & & & \\
\hline $\begin{array}{l}\text { Lake George, } \\
\text { FL }\end{array}$ & Open lake & 40 & 2 & 100 & 4000 & 0.5 & 1 & 1 & \\
\hline $\begin{array}{l}\text { Lake George, } \\
\text { FL }\end{array}$ & Neck and tail & 40 & 2 & 10 & 400 & 1.5 & 1 & 1 & \\
\hline $\begin{array}{l}\text { Lake } \\
\text { Balaton, } \\
\text { Hungary }\end{array}$ & $\begin{array}{l}\text { One of three } \\
\text { acceptable } \\
\text { parameter sets }\end{array}$ & 19 & 15 & 23.5 & 447 & 0.95 & & 0.88 & $\begin{array}{l}\text { Luettich et al. } \\
1990\end{array}$ \\
\hline $\begin{array}{l}\text { Thomsons } \\
\text { Lake, } \\
\text { Australia }\end{array}$ & $\begin{array}{l}\text { One of two } \\
\text { alternate } \\
\text { parameter sets }\end{array}$ & 2.6 & 2 & 766 & 1992 & 0 & 1 & 1 & $\begin{array}{l}\text { Bailey and } \\
\text { Hamilton } \\
1997\end{array}$ \\
\hline $\begin{array}{l}\text { Lake St. } \\
\text { Clair, MI }\end{array}$ & $\begin{array}{l}\text { Range of } \\
\text { Parameters } \\
\text { from } 19 \text { data } \\
\text { sets }\end{array}$ & $\begin{array}{l}1.7 \text { to } \\
121\end{array}$ & 1 to 4 & $\begin{array}{l}17 \text { to } \\
158\end{array}$ & $\begin{array}{l}53 \text { to } \\
3600\end{array}$ & 0 & 1 & 1 & $\begin{array}{l}\text { Hawley and } \\
\text { Lesht } 1992\end{array}$ \\
\hline $\begin{array}{l}\text { Lake } \\
\text { Christina, } \\
\text { MN }\end{array}$ & $\begin{array}{l}\text { No-macrophyte } \\
\text { conditions }\end{array}$ & 2.6 & 100 & 207 & 538 & 1.4 & & 0.67 & $\begin{array}{l}\text { James et al. } \\
2004 a\end{array}$ \\
\hline $\begin{array}{l}\text { Peoria Lake, } \\
\text { IL }\end{array}$ & & 47 & 120 & 207 & 9658 & 2.3 & 1 & 0.67 & $\begin{array}{l}\text { James et al. } \\
2004 b\end{array}$ \\
\hline
\end{tabular}

\section{SEDZL application to Lake George}

The Lake George data set consists primarily of TSS and POC observations in the water column, along with the composition of a few sediment cores. The previous suspended solids model was selected, in part, because its application required minimal data beyond that which was available. Parameters for which observations were not available were evaluated through recursive application of the model and comparison with observed properties. SEDZLJ is more demanding in terms of required parameters and application should 
be accompanied by a specific data collection effort. In the absence of observations, parameters for this test are derived from the previous application, when possible, or default values provided by the contractor with the code are employed. No optimization of the SEDZLJ parameters, through recursive model application, is attempted. The selected parameter values suit the purposes of the tests - to evaluate the model under prototype conditions and to compare results with an alternate application.

\section{Settling velocities}

Settling velocities for inorganic particles are computed within the SEDZLJ code based on specified particle diameters. Diameters for the three inorganic classes were adapted from default values supplied by the contractor (Table 4). Settling velocities for POC were characteristic of values used in eutrophication models (Table 4).

Table 4. Particle diameters and settling velocities for SEDZL application.

\begin{tabular}{|l|l|l|}
\hline Particle & Diameter $\mu \mathrm{m}$ & Settling Velocity $\mathrm{m} \mathrm{d}^{-1}$ \\
\hline Clay/Silt & 5 & 1.3 \\
\hline Fine Sand & 90 & 396 \\
\hline Medium Sand & 500 & 5069 \\
\hline LPOC & & 0.1 \\
\hline RPOC & & 0.1 \\
\hline
\end{tabular}

\section{Bed composition}

Analysis of the sediment cores suggested that bed sediments in the neck, which are subject to regular, high, shear stress, were denser and contained less carbon than sediments in the open lake, subject to irregular, lower shear stress. The sediment bed was divided into five layers. The upper four layers were initially $5 \mathrm{~cm}$ thick, the bottom layer was $10 \mathrm{~cm}$. Initial composition of the upper four layers was based on observations (Table 5). The bottom layer was assigned composition of medium sand to provide a stable base resistant to erosion in the event the upper four layers eroded away. Initial bed composition in the tail, also subject to high shear stress, was assigned the same values as the neck. 
Table 5. Initial bed characteristics for SEDZ $\sqcup$ application.

\begin{tabular}{|l|l|l|}
\hline Characteristic & Neck, Tail & Lake \\
\hline Bulk Density, upper 4 layers, $\mathrm{g} \mathrm{cm}^{-3}$ & 1.2 & 0.4 \\
\hline Clay/Silt Fraction, upper 4 layers & 0 & 0.31 \\
\hline Fine Sand Fraction, upper 4 layers & 0.496 & 0.303 \\
\hline Medium Sand Fraction, upper 4 layers & 0.496 & 0.303 \\
\hline LPOC Fraction, upper 4 layers & 0.004 & 0.042 \\
\hline RPOC Fraction, upper 4 layers & 0.004 & 0.042 \\
\hline Bulk Density, bottom layer, g cm ${ }^{-3}$ & 1.2 & 1.2 \\
\hline Clay/Silt Fraction, bottom layer & 0 & 0 \\
\hline Fine Sand Fraction, bottom layer & 0 & 0 \\
\hline Medium Sand Fraction, bottom layer & 1 & 1 \\
\hline LPOC Fraction, bottom layer & 0 & 0 \\
\hline RPOC Fraction, bottom layer & 0 & 0 \\
\hline
\end{tabular}

\section{Critical shear stress}

Much of the parameter assignment for Lake George is based on the division into regions dominated by current-generated shear stress (neck and tail) versus regions dominated by wave-generated shear stress (open lake). Critical shear stresses for surficial sediments in these regions were adapted from the previous application (Table 6). Critical shear stress was assumed to increase with depth into the bed. An artificial, high value was assigned to the bottom layer to prevent erosion. Critical shear stress for deposition, 0.5 dyne $\mathrm{cm}^{-2}$, was selected from the range of values recommended in the SEDZLJ users' guide.

Table 6. Critical shear stress for erosion, SEDZU application.

\begin{tabular}{|l|l|l|}
\hline Layer & Neck, Tail, dyne $\mathrm{cm}^{-2}$ & Lake, dyne $\mathrm{cm}^{-2}$ \\
\hline 1 & 1.5 & 5 \\
\hline 2 & 1.65 & 0.55 \\
\hline 3 & 1.82 & 0.61 \\
\hline 4 & 2 & 0.67 \\
\hline 5 & 999 & 999 \\
\hline
\end{tabular}




\section{Erosion rate}

SEDZLJ calculation of erosion rate $\left(\mathrm{cm} \mathrm{s}^{-1}\right)$ relies on two parameters, A and $\mathrm{n}$ (Equation 8). Previously determined potential erosion rates for the system, in units consistent with the previous model, were $400 \mathrm{~g} \mathrm{~m}^{-2} \mathrm{~d}^{-1}$ for the neck and tail and $4000 \mathrm{~g} \mathrm{~m}^{-2} \mathrm{~d}^{-1}$ for the open lake. Division of these rates by bulk density ( $1.2 \mathrm{~g} \mathrm{~cm}^{-3}$ in the neck and $0.4 \mathrm{~g} \mathrm{~cm}^{-3}$ in the lake) followed by units conversion yields characteristic values for parameter A: $3.86 \times 10^{-7}$ in the neck and tail; $1.16 \times 10^{-5}$ in the lake. Parameter $\mathrm{n}$ was assigned a value of 1 , consistent with the previous application. The exponent in the cohesive sediment hiding factor was assigned the value 0.85 recommended in the SEDZLJ users' guide.

\section{Results}

The SEDZLJ application was "spun up" from initial conditions for a period of three years. Conditions in the water column and bed at the end of the spin-up were used as initial conditions for a three-year application. The integration time-step was 1 minute.

\section{Time series comparisons}

Solids observations in the water column are available at four locations (Figure 17):

- MSJFGF - in the northern neck, subject to periodic current-generated shear stresses

- LG12 - At the juncture between the neck and open lake, shielded from wind-generated waves

- MSJLGM - At the center of the open lake, subject to shear stresses from wind-generated waves

- MSJLGS - At the southern end of the lake, influenced by inflows from the riverine tail

TSS comparisons at the center of the lake reveal characteristic differences between the two applications: computed TSS values in the previous application are "spikey" with high concentrations that settle out rapidly while computed TSS in SEDZLJ attain lower concentrations but remain in the water column longer (Figures 18 - 20). TSS computations from the previous model also demonstrate the presence of the $2 \mathrm{gm} \mathrm{m}^{-3}$ background concentration, which is absent from SEDZLJ. The longer residence time of 
particles in the water represented by SEDZLJ can be attributed to the lower settling velocities of SEDZLJ clay/silt versus fixed solids in the previous model (1.3 $\left.\mathrm{m} \mathrm{d}^{-1} \mathrm{vs} .40 \mathrm{~m} \mathrm{~d}^{-1}\right)$ and of SEDZLJ LPOC and RPOC versus identical particles in the previous model (0.1 m d-1 vs. $\left.40 \mathrm{~m} \mathrm{~d}^{-1}\right)$. Although SEDZLJ sand components possess higher settling velocities than fixed solids in the previous model, computed sand fractions are negligible compared to clay/silt (Figure 21). The highly variable nature of the computations and the scarcity of observations at this location prevent a visual judgment of the accuracy of one model versus the other.

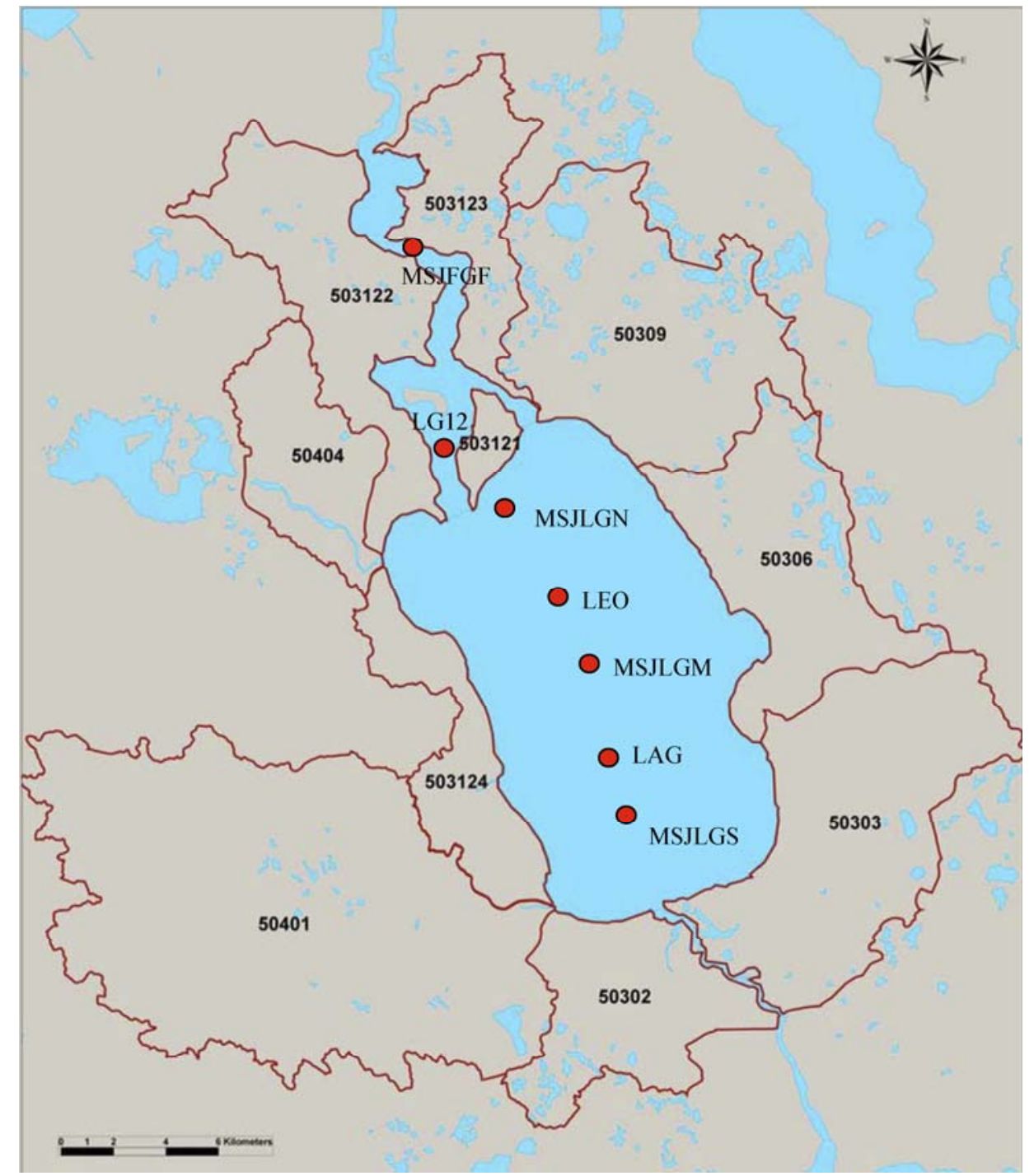

Figure 17. Lake George sample stations. 


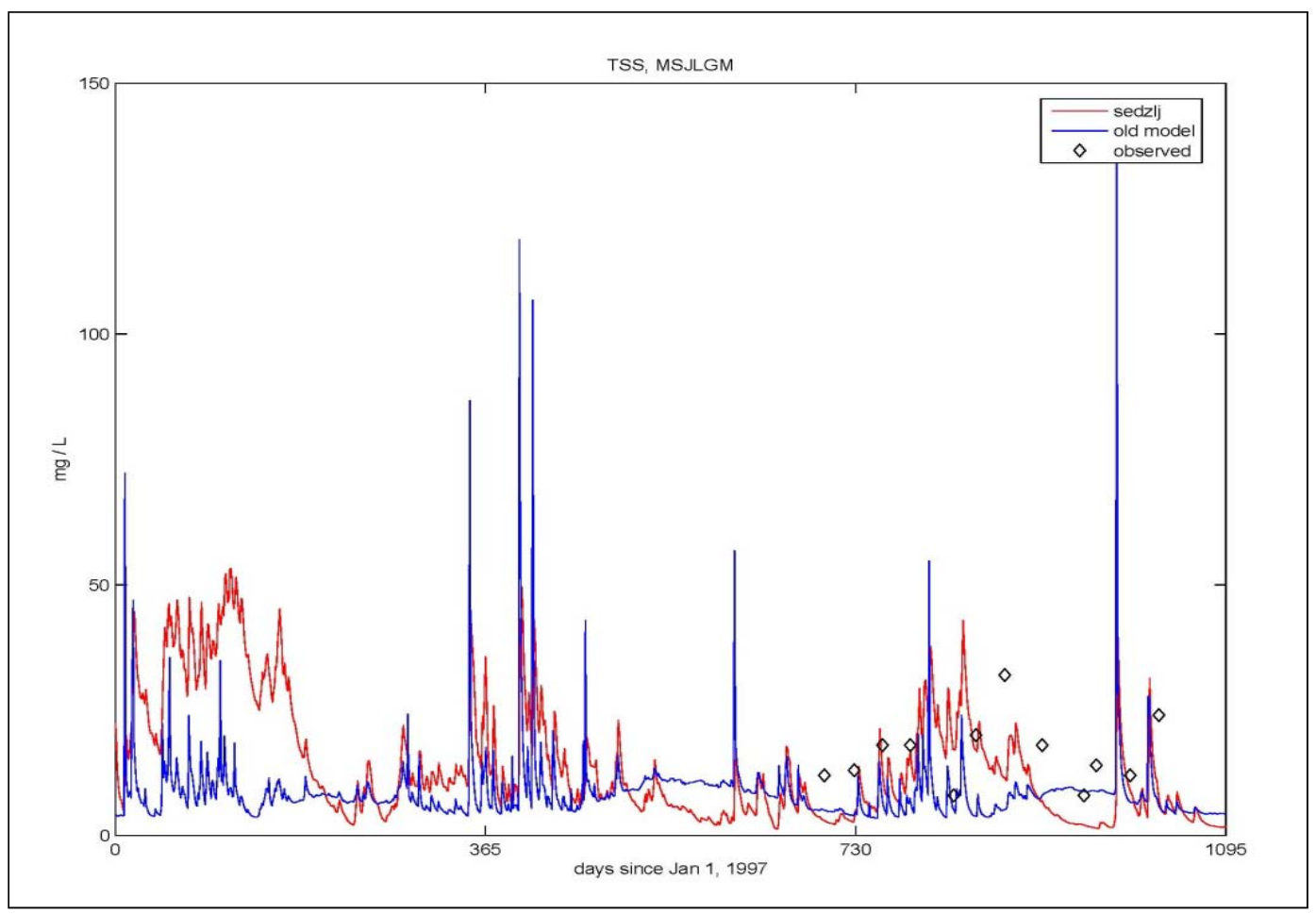

Figure 18. Computed and observed TSS at station MSJLGM for two suspended solids models, SEDZU and an "old" model based on long-term equilibrium between deposition and resuspension.

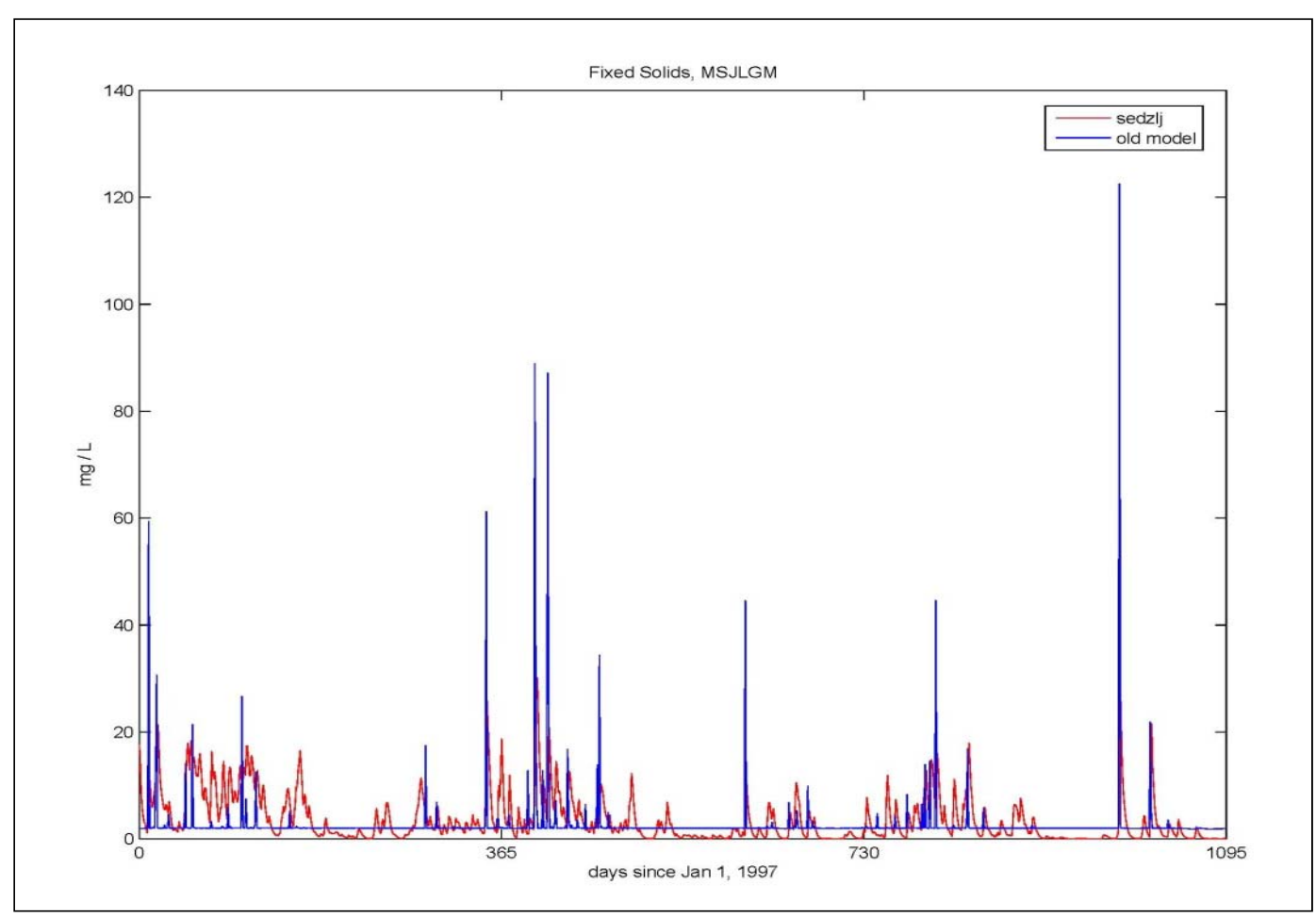

Figure 19. Computed fixed solids at station MSJLGM for two suspended solids models, SEDZU and an "old" model based on long-term equilibrium between deposition and resuspension. 


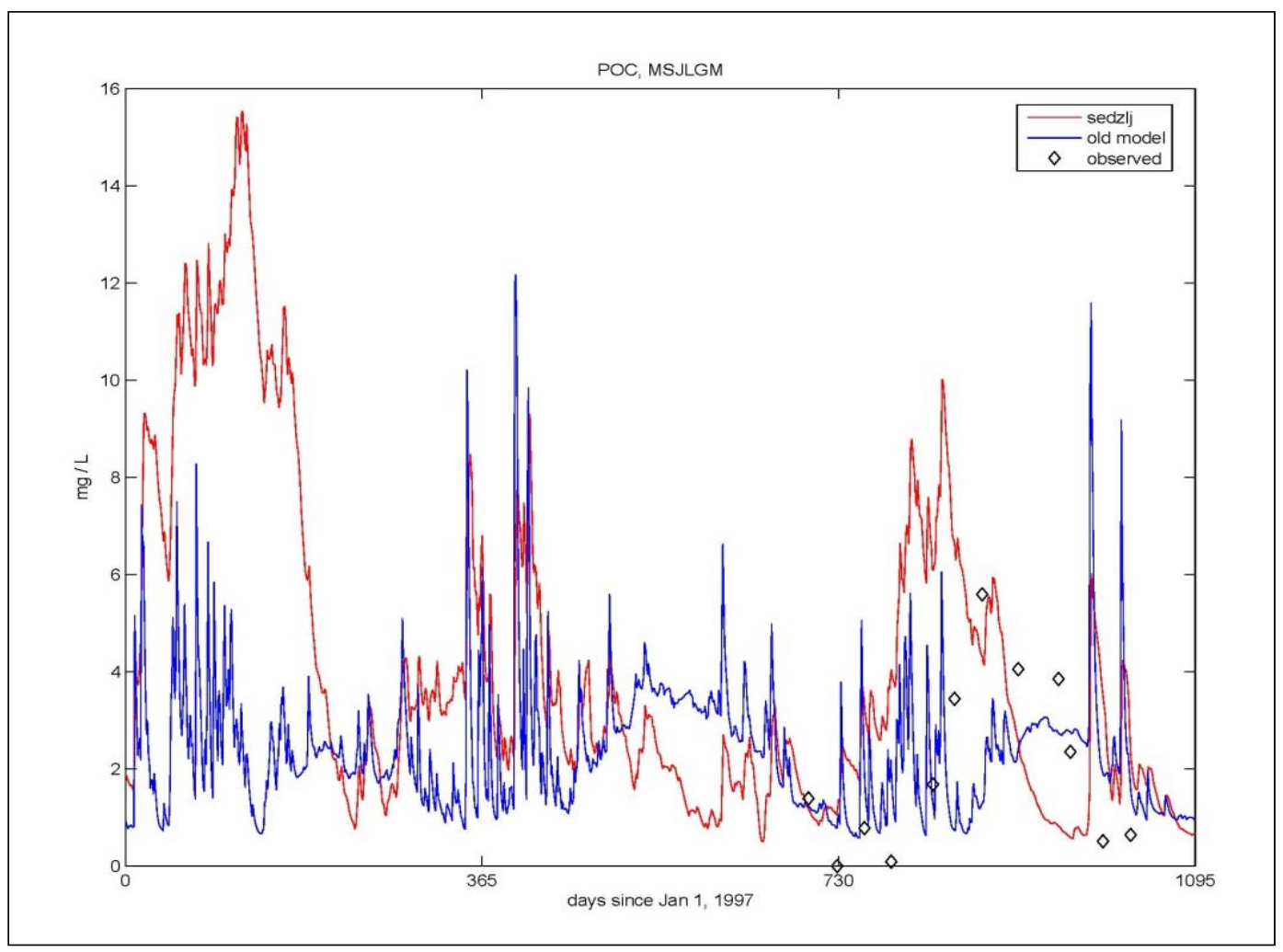

Figure 20. Computed and observed POC at station MSJLGM for two suspended solids models, SEDZL and an "old" model based on long-term equilibrium between deposition and resuspension.

In the northern neck, the higher concentrations and rapid resuspension/ deposition provided by the previous model apparently result in better representation of the observations than from SEDZLJ (Figure 22). It should be noted that the previous model was calibrated to match the observations while no adjustment was performed to the initial SEDZLJ parameter set. Presumably, SEDZLJ could be adjusted to improve performance in this region. The characteristic differences between the two representations noted at MSJLGM prevail at LG12 (Figure 23) and MSJLGS (Figure 24) as well.

\section{Solids budgets}

Although there are solids inputs to Lake George from springs and, during storms, from distributed flows, the preponderance of solids enter at the southern end, from the Upper St. Johns River. The only exit is at the northern end, into the Lower St. Johns. For practical purposes, lake solids budgets can be constructed using mass fluxes at these two locations. The budgeting algorithms in ICM were used to create monthly (Figures 25 and 26) and three-year average budgets for fixed solids and POC (Table 7). For 
both model versions, fixed solids exports exceed fixed solids loads. For SEDZLJ, fixed solids outflow exceeds inflow by a factor of six, indicating net erosion from the sediment bed. The excess is largely in the form of fine sand; a small import of medium sand is computed. For the previous model, fixed solids outflow exceeds inflow by a factor of 30 . This excess is paradoxical, since the model is constructed around the concept of longterm equilibrium in the sediment bed. The inclusion of settling velocity in the erosion term is intended to promote bed equilibrium.

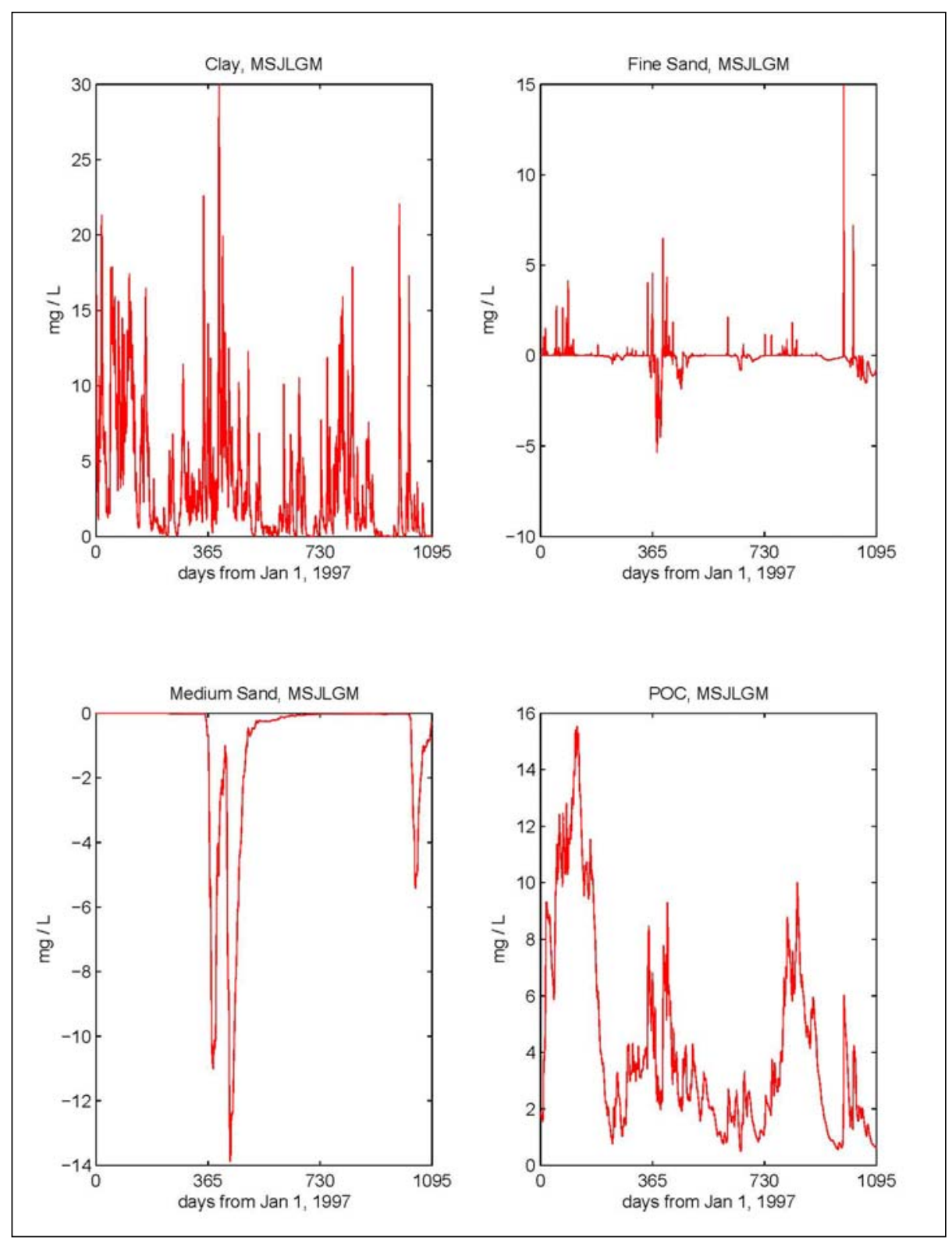

Figure 21. Computed individual sediment components from SEDZL at station MSJLGM. 


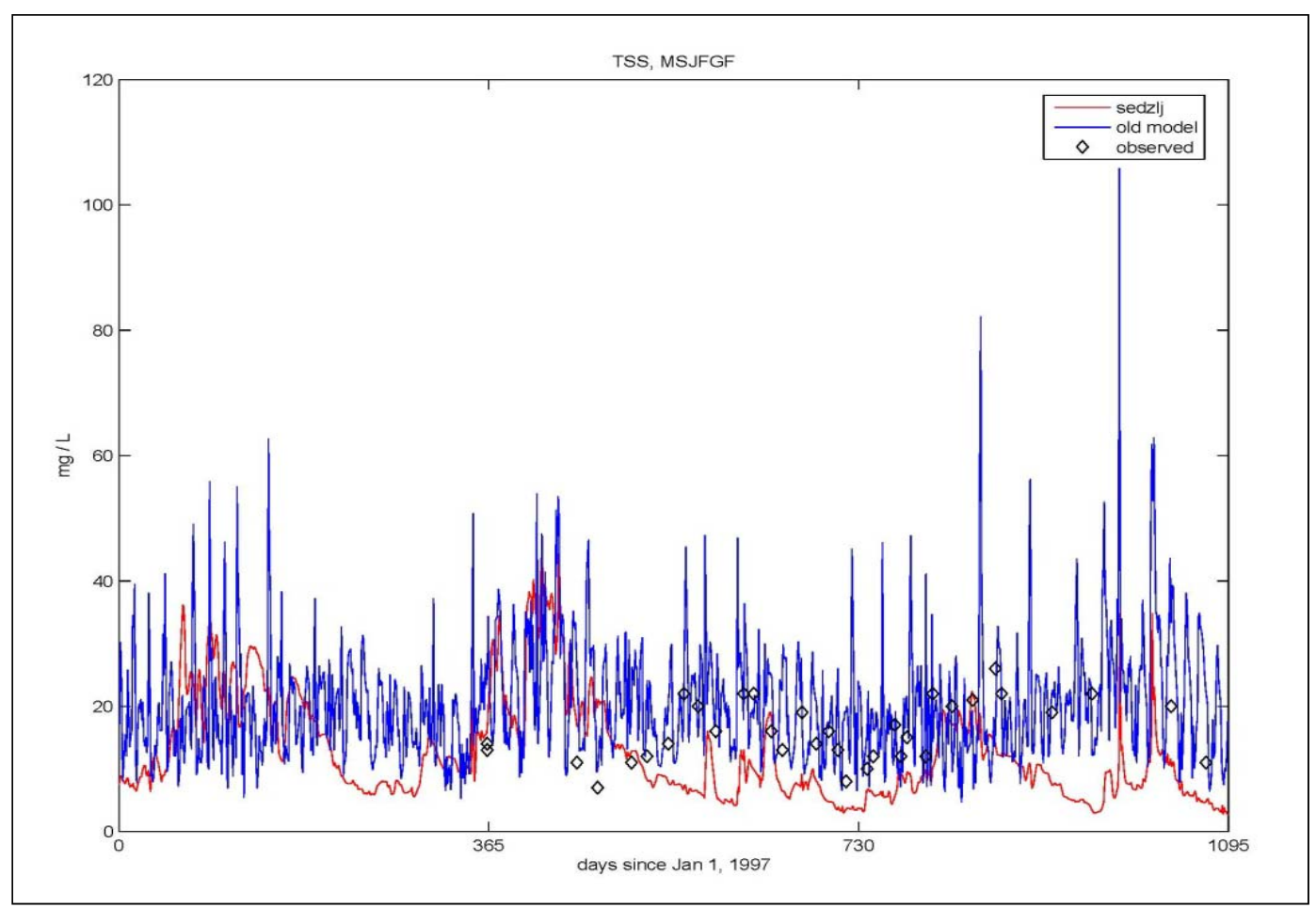

Figure 22. Computed and observed TSS at station MSJFGF for two suspended solids models, SEDZU and an "old" model based on long-term equilibrium between deposition and resuspension.

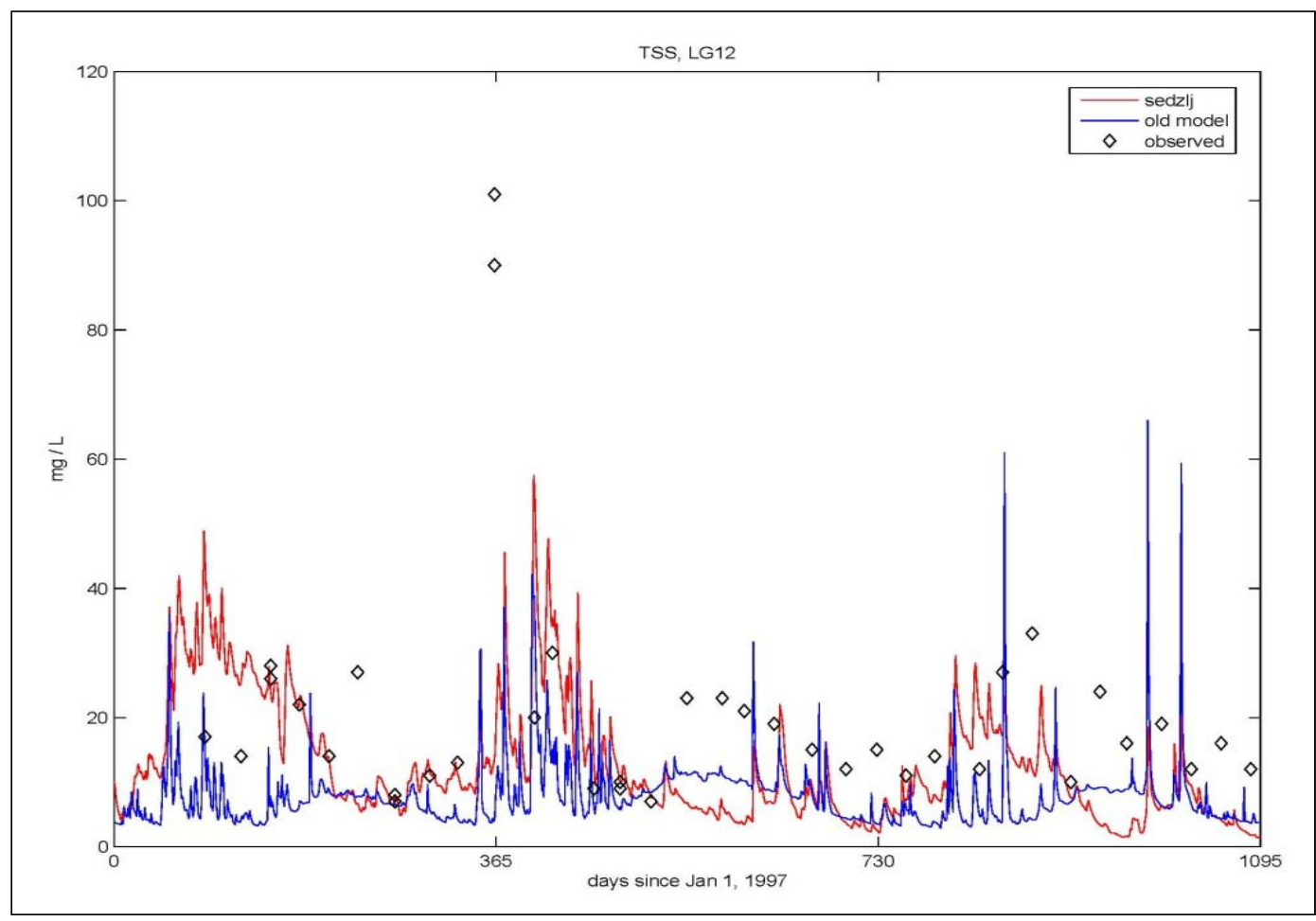

Figure 23. Computed and observed TSS at station LG12 for two suspended solids models, SEDZU and an "old" model based on long-term equilibrium between deposition and resuspension. 


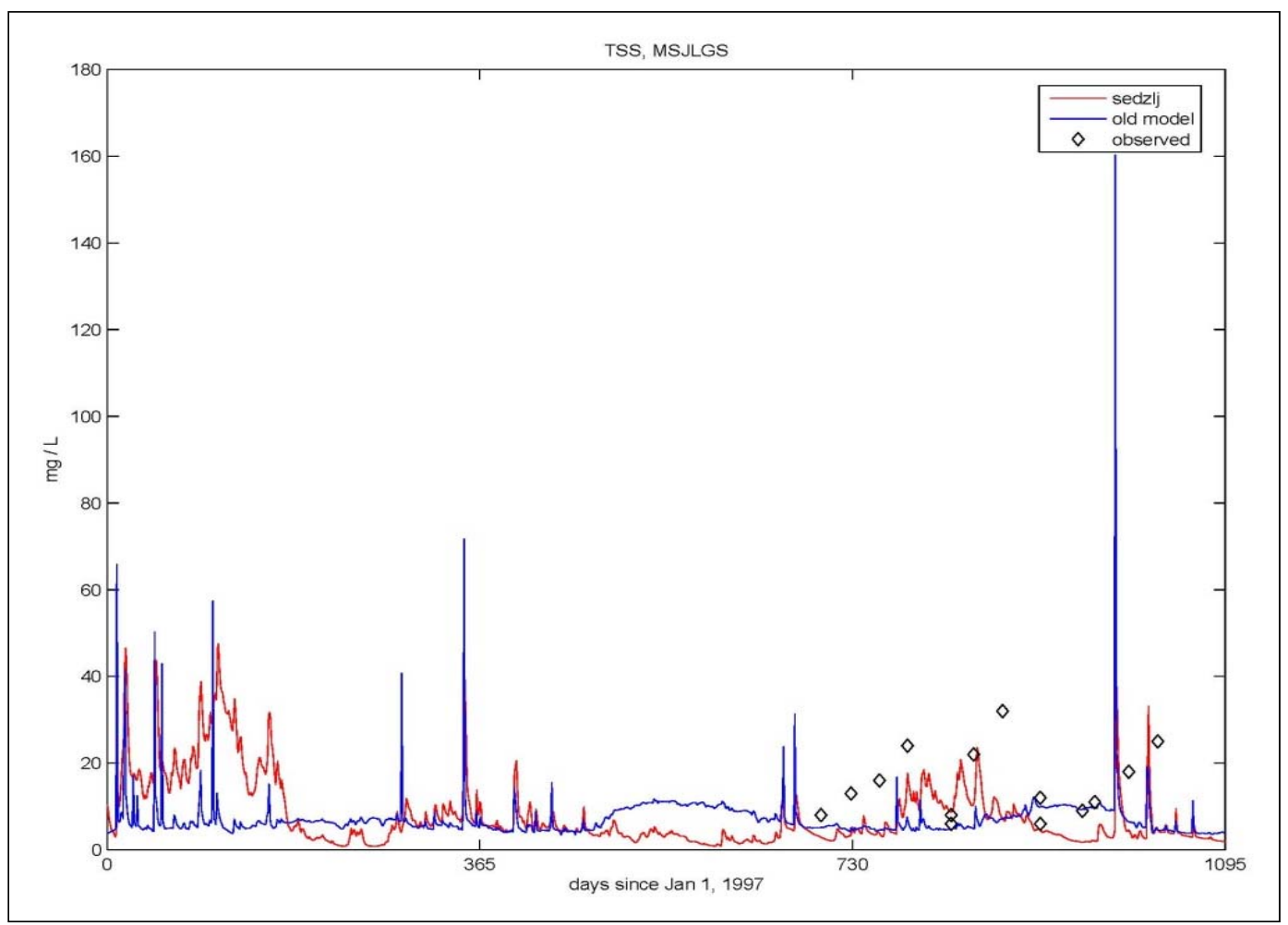

Figure 24. Computed and observed TSS at station MSJLGS for two suspended solids models, SEDZU and an "old" model based on long-term equilibrium between deposition and resuspension.

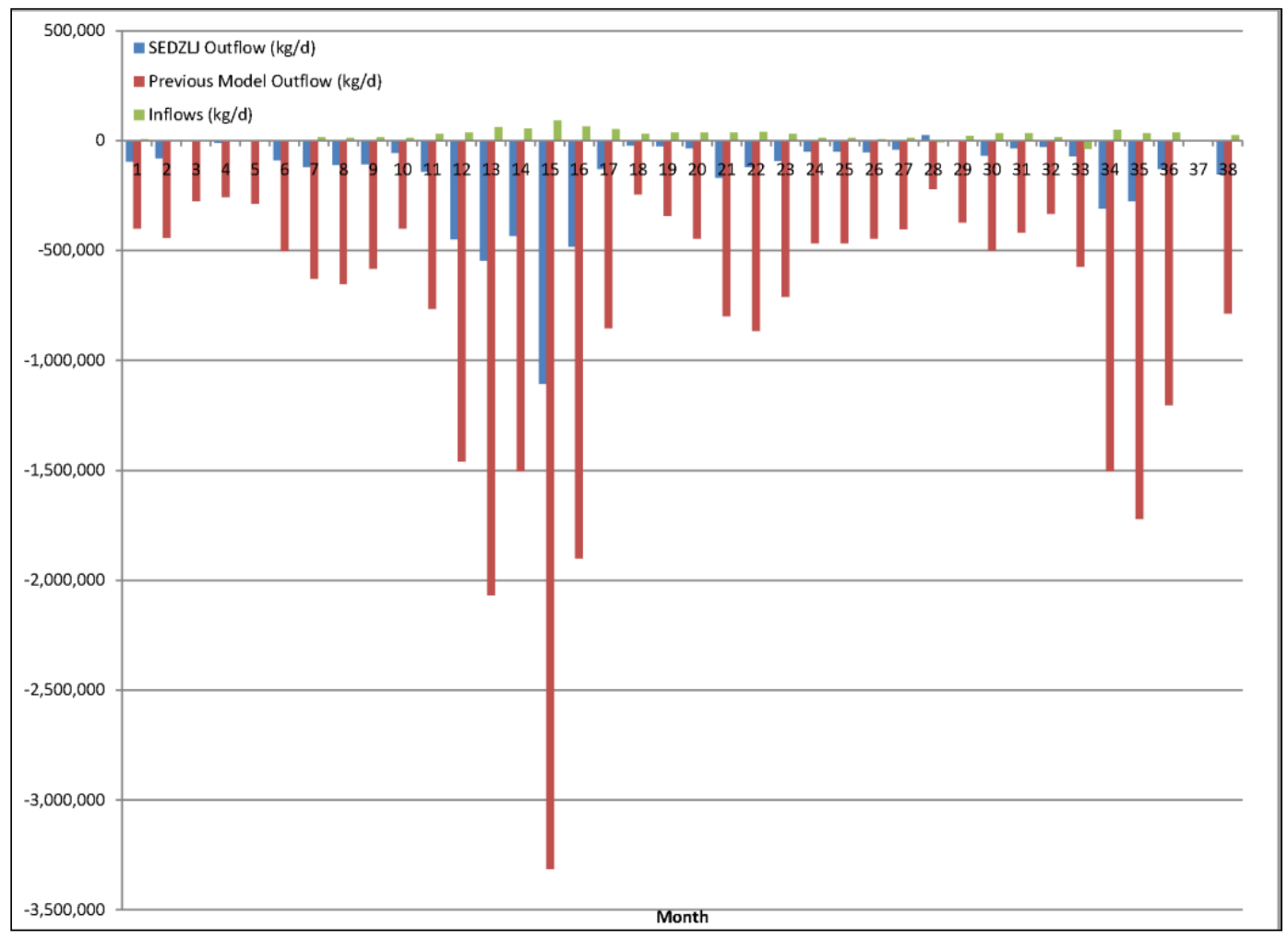

Figure 25. Monthly fixed solids budget $\left(\mathrm{kg} \mathrm{d}^{-1}\right)$ from two models. 


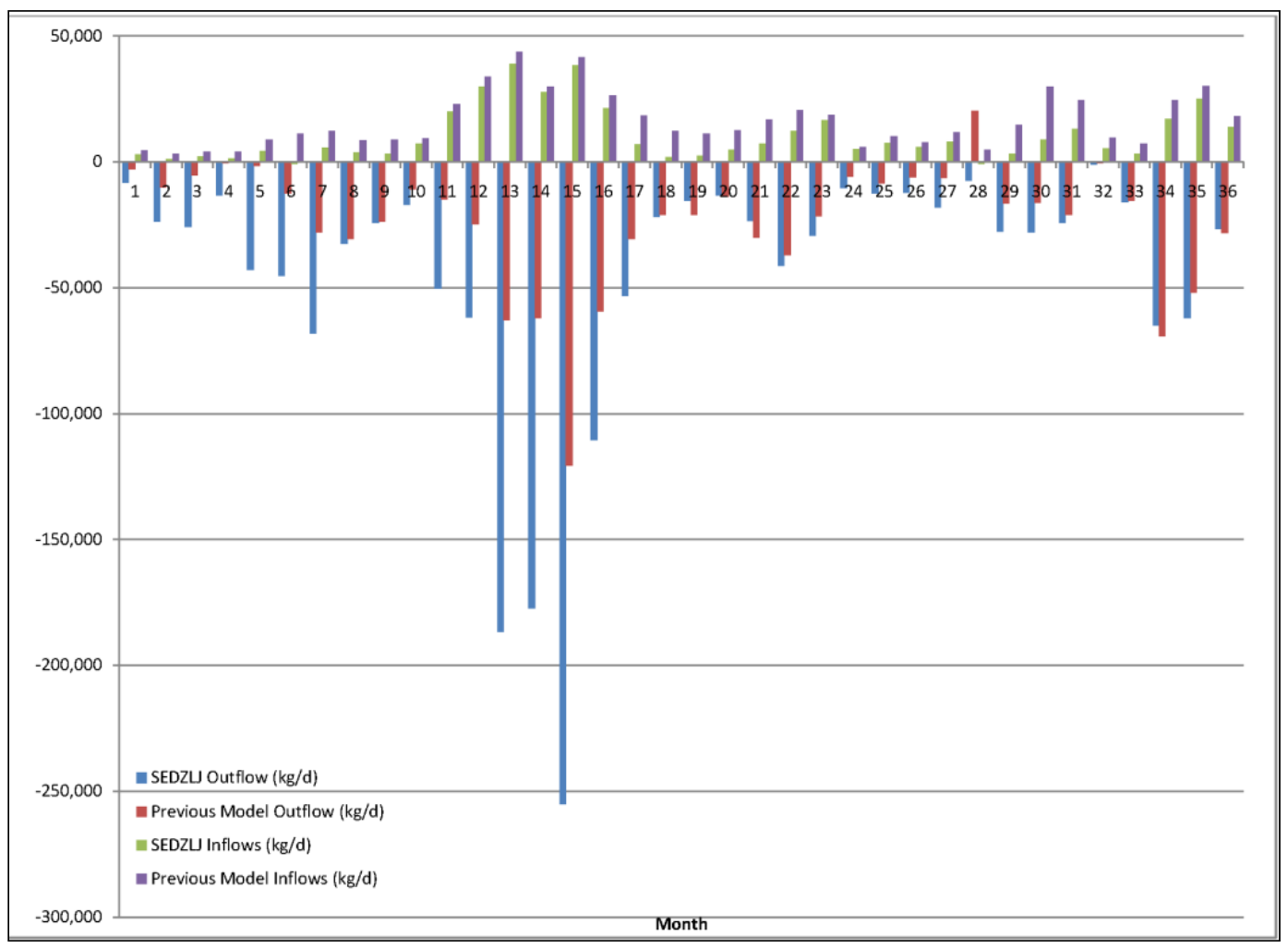

Figure 26. Monthly POC budgets $\left(\mathrm{kg} \mathrm{d}^{-1}\right)$ from two models.

Table 7. Solids budgets for two models, averaged over the simulation period.

\begin{tabular}{|l|l|l|l|l|}
\hline \multirow{2}{*}{ Budget } & \multicolumn{2}{|c|}{ SEDZ } & \multicolumn{2}{c|}{ Previous Model } \\
\cline { 2 - 5 } & Inflow & Outflow & Inflow & Outflow \\
\hline Clay/Silt, kg d ${ }^{-1}$ & 8,794 & 20,923 & & \\
\hline Fine Sand, kg d ${ }^{-1}$ & 8,798 & 132,336 & & \\
\hline Medium Sand, kg d-1 & 9,152 & -714 & & \\
\hline Fixed Solids, kg d-1 & 24,208 & 152,546 & 24,208 & 786,652 \\
\hline POC, kg d $^{-1}$ & 10,390 & 45,882 & 16,175 & 24,230 \\
\hline
\end{tabular}

POC outflow computed by SEDZLJ exceeds inflow by roughly the same factor as fixed solids, once again indicating net erosion of the bed. The previous model POC inflow and outflow are roughly in balance, in contrast to fixed solids. The contrast is attributed to modeling of the complete carbon cycle, which includes mass balance in the bed. These results indicate that rigorous sediment transport modeling must include bed mass balance. Although the present SEDZLJ representation of Lake George is out of balance, the formulation provides for balance to be achieved through additional tuning of the model, ideally aided by data collection. The previous model does not provide this opportunity although, perhaps, 
whole-lake mass balances could be employed in concert with parameter evaluation to obtain a consistent model using the simpler formulation.

\section{Negative sand}

Computation of negative sand concentration was noted, in particular at 365 days into the simulation (Figure 21). Near this time, quantities of sand were eroded from the riverine portion by a flood event and deposited in the lake. Apparently numerical instability caused negative concentrations. The settling velocity of medium sand is $5069 \mathrm{~m} \mathrm{~d}^{-1}$ or $5.9 \mathrm{~cm} \mathrm{~s}^{-1}$. Medium sand settles through a water column layer of average thickness in $25 \mathrm{~s}$ while the integration time-step is $60 \mathrm{~s}$. The rapid settling produced negative concentrations, which persisted after the event passed. Experiments were attempted in which the mass allowed to settle in a time-step was restricted to the mass in a layer, but negative concentrations persisted. In reality, this model is not intended to transport medium to coarse sand. The role of medium sand in the simulation is to provide a substrate of stable material in the bed. Sand should be transported primarily as bedload, which is absent from this model version. The negative sand concentrations are harmless but must be noted.

\section{Statistical summary}

Statistical summaries were prepared for TSS and POC computed by both models and compared to observations. In keeping with summaries of previous ICM simulations, computed statistics included mean difference (MD):

$$
M D=\frac{\sum(P-O)}{n}
$$

where

$$
\begin{aligned}
& O=\text { observation } \\
& P=\text { computation } \\
& n=\text { number of observations }
\end{aligned}
$$

and absolute mean difference (AMD)

$$
A M D=\frac{|P-O|}{n}
$$


Positive MD indicates the model computations exceed the observations, on average. Negative MD indicates the model computations are less than observations, on average. The AMD statistic characterizes the magnitude of the difference between individual computations and observations, regardless of sign. Correlations between computations and observations were calculated, as well.

Statistical summaries indicate the two models are equivalent in their representation of the observations (Table 8). Both models under-predict TSS by the same amount, $\approx 6 \mathrm{~g} \mathrm{~m}^{-3}$, and over-predict POC by $\approx 1 \mathrm{~g} \mathrm{~m}^{-3}$. Correlation coefficients between computations and observations are effectively zero. The equivalence of the two computations is interesting in view of the two different representations of the system. The previous model described a system with a constant background solids concentration and rapid resuspension and deposition. SEDZL describes a system with no background concentration and slower resuspension and deposition. Lack of correlation indicates the difficulty in exactly matching sparse, sporadic, observations with the model. Rigorous solids computation in this system requires a comprehensive observational program including field samples and sediment characteristics. Nevertheless, the goals of testing SEDZLJ in a prototype application and of comparing results with an alternative model have been fulfilled.

Table 8. Statistical summary of computations from two models.

\begin{tabular}{|l|l|l|}
\hline Component & Previous Model & SEDZப \\
\hline TSS, mean difference, $\mathrm{g} \mathrm{m}^{-3}$ & -5.2 & -6.9 \\
\hline TSS, absolute mean difference, $\mathrm{g} \mathrm{m}^{-3}$ & 9.8 & 10 \\
\hline POC, mean difference, $\mathrm{g} \mathrm{m}^{-3}$ & 0.3 & 1.6 \\
\hline POC, absolute mean difference, $\mathrm{g} \mathrm{m}^{-3}$ & 1.6 & 2.7 \\
\hline
\end{tabular}




\section{Summary and Conclusions}

The preceding chapters described the formulation of the SEDZLJ sediment transport model, coupling of the model with the ICM eutrophication model, validation of the combined codes on a simplified grid, and application of the combined codes to a prototype system.

Code validation tests indicated that the codes are correctly coupled. The combined codes met specified performance criteria, including:

1. Mass conservation in water and bed.

2. Limited sensitivity to variations in model time-step.

3. Settling of new ICM state variables through model water column agrees with settling of original ICM state variables.

4. Transport of new ICM state variables agrees with transport of original ICM state variables.

5. Armoring of bed.

6. Smooth erosion of bed.

7. Reasonable behavior of the model for accumulation in the bed with no erosion.

Additional evaluation and testing were performed through application of the combined models to a prototype system, Lake George, Florida. The code performed reasonably through a three-year simulation. The tests indicated, however, that realistic application of SEDZLJ requires an extensive set of field and laboratory observations.

One characteristic revealed by the prototype simulations was the computation of negative sand in the water column. The negative concentrations apparently result from numerical aberrations caused by the rapid settling of sand through the model water column. Stability criteria indicate model time-steps $\approx 10 \mathrm{~s}$ might be required to properly compute settling of sand. In reality, the present model is not intended to transport medium to coarse sand, since bedload is not represented. The role of medium sand in the model is primarily to anchor the bed. 
The integration time-step in the present model was reduced to $60 \mathrm{~s}$ versus $15 \mathrm{~min}$ for application of the ICM eutrophication algorithms to the prototype system. As a result of the reduced time-step and additional computational demands imposed by the SEDZLJ bed model, the computation time of the combined ICM/SEDZLJ models increases tremendously over the basic eutrophication model. A three-year simulation of Lake George eutrophication consumes $4 \mathrm{hr}$ on a desktop PC, while a three-year simulation of suspended solids, using SEDZLJ, consumes four days. This increase is despite the fact that the eutrophication simulation includes 26 state variables, while the suspended solids simulation includes only six. Although computation time can be reduced by moving to a faster computer, the practical application of the combined codes, in their present state, is severely limited. Practicality will be further limited when computation of toxicants is added to the combined codes. Efforts to convert the combined codes to parallel computation, via domain decomposition, are presently underway. Simultaneously, ICM/SEDZLJ is being combined with the RECOVERY toxicant model (Boyer et al. 1994), after which a second round of parallelization is anticipated. 


\section{References}

Bailey, M., and D. Hamilton. 1997. Wind induced sediment resuspension: a lake-wide model. Ecological Modeling 99: 217-228.

Boyer, J., S. Chapra, C. Ruiz, and M. Dortch. 1994. RECOVERY, A mathematical model to predict temporal response of surface water to contaminated sediments. Technical Report W-94-4. Vicksburg MS: U.S. Army Engineer Waterways Experiment Station.

Cerco, C., and M. Noel. 2009. Incorporation of wind-driven sediment resuspension into the CE-QUAL-ICM eutrophication model of Lake George, Florida. Palatka, FL: Report to the St. Johns River Water Management District (copies available from the first author Carl.F.Cerco@usace.army.mil).

Cheng, N. 1997. A simplified settling velocity formula for sediment particle. Journal of Hydraulic Engineering 123(2): 149-152.

DiToro, D. 2001. Sediment flux modeling. New York: John Wiley and Sons, 27-55.

Hawley, N., and B. Lesht. 1992. Sediment resuspension in Lake St. Clair. Limnology and Oceanography 37(8): 1720-1737.

James, W., E. Best, and J. Barko. 2004b. Sediment resuspension and light attenuation in Peoria Lake: can macrophytes improve water quality in this shallow system? Hydrobiologia 515: 193-201.

James, W., J. Barko, and M. Butler. 2004a. Shear stress and sediment resuspension in relation to submersed macrophyte biomass. Hydrobiologia 515: 181-191

Jones, C., and W. Lick. 2001. SEDZLJ, A sediment transport model. Santa Barbara, CA: Department of Mechanical and Environmental Engineering, University of California.

Karickhoff, S., D. Brown, and T. Scott. 1979. Sorption of hydrophobic pollutants on natural sediments. Water Research 13:241-248.

Luettich, R., D. Harleman, and L. Somlyody. 1990. Dynamic behavior of suspended sediment concentrations in a shallow lake perturbed by episodic wind events. Limnology and Oceanography 35(5): 1050-1067.

Tetra Tech Inc. 2007. The Environmental Fluid Dynamics Code, Theory and computation, Volume 2: Sediment and contaminant transport and fate. Fairfax VA: Tetra Tech Inc.

Warner, J., C. Sherwood, R. Signell, C. Harris, and H. Arango. 2008. Development of a three-dimensional, regional, coupled wave, current, and sediment transport model. Computers \& Geosciences 34:1284-1306. 
Weston Solutions Inc. 2006. Final model documentation report: Modeling study of PCB contamination in the Housatonic River. Contract No. DACW33-00-D-0006. West Chester, PA: Weston Solutions Inc. 


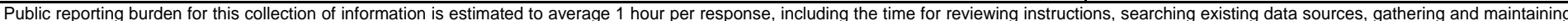

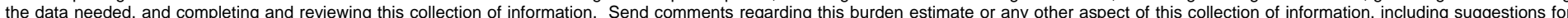

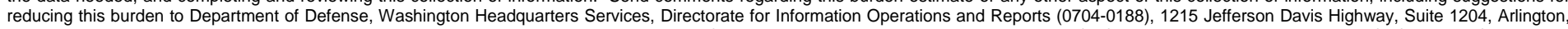

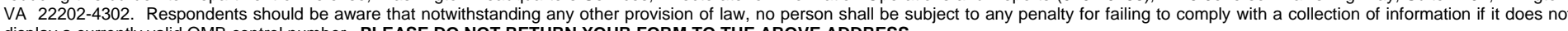
display a currently valid OMB control number. PLEASE DO NOT RETURN YOUR FORM TO THE ABOVE ADDRESS.
1. REPORT DATE (DD-MM-YYYY) 2. REPORT TYPE
3. DATES COVERED (From - To)

August 2012 Final

\section{TITLE AND SUBTITLE}

Combining the ICM Eutrophication Model with the SEDZLJ Sediment Transport Model

5a. CONTRACT NUMBER

5b. GRANT NUMBER

5c. PROGRAM ELEMENT NUMBER

\section{AUTHOR(S)}

Carl F. Cerco

5d. PROJECT NUMBER

5e. TASK NUMBER

5f. WORK UNIT NUMBER

\section{PERFORMING ORGANIZATION NAME(S) AND ADDRESS(ES)}

8. PERFORMING ORGANIZATION REPORT NUMBER

Environmental Laboratory

U.S. Army Engineer Research and Development Center

ERDC/EL TR-12-17

3909 Halls Ferry Road

Vicksburg, MS 39180

\section{SPONSORING / MONITORING AGENCY NAME(S) AND ADDRESS(ES)}

\section{U.S. Army Corps of Engineers}

Washington, DC 20314-1000

11. SPONSOR/MONITOR'S REPORT NUMBER(S)

\section{DISTRIBUTION I AVAILABILITY STATEMENT}

Approved for public release; distribution is unlimited.

\section{SUPPLEMENTARY NOTES}

\section{ABSTRACT}

This report describes the formulation of the SEDZLJ sediment transport model, coupling of the model with the ICM eutrophication model, validation of the combined codes on a simplified grid, and application of the combined codes to a prototype system.

The code validation tests indicate the codes are correctly coupled. The combined codes meet specified performance criteria including:

1. Mass conservation in water and bed.

2. Limited sensitivity to variations in model time-step.

3. Settling of new ICM state variables through model water column agrees with settling of original ICM state variables.

4. Transport of new ICM state variables agrees with transport of original ICM state variables.

5. Sediment bed will armor.

6. Bed erodes away smoothly.

7. Model behaves reasonably for accumulation in the bed with no erosion.

Additional evaluation and testing were performed through application of the combined models to a prototype system: Lake George, Florida. The codes perform reasonably through a three-year simulation. The tests indicate, however, that realistic application of SEDZLJ requires an extensive set of field and laboratory observations.

\section{SUBJECT TERMS}

Contaminant transport and fate

ICM water quality model

16. SECURITY CLASSIFICATION OF:

\section{a. REPORT}

Unclassified

\section{b. ABSTRACT}

Unclassified
Lake George, Florida

SEDZLJ sediment transport model

Sediment erosion and deposition
Sediment transport

17. LIMITATION OF ABSTRACT

18. NUMBER
OF PAGES
46

19a. NAME OF RESPONSIBLE PERSON

19b. TELEPHONE NUMBER (include area code) 